\title{
Productivity Analysis of Volume Fractured Wells under Different Working Systems
}

\author{
Hongfei Ma $\mathbb{D}^{1,2}$ Wenqi Zhao, ${ }^{2}$ Meng Sun, ${ }^{2}$ Xiaodong Wang $\mathbb{D},{ }^{1}$ Lun Zhao, ${ }^{2}$ Chunmei Zou, ${ }^{1,2}$ \\ and Bo Wang ${ }^{1}$ \\ ${ }^{1}$ School of Energy Resources, China University of Geosciences (Beijing), Beijing 100083, China \\ ${ }^{2}$ Research Institute of Petroleum Exploration and Development, China National Petroleum Corporation, Beijing 100083, China \\ Correspondence should be addressed to Xiaodong Wang; wxd_cug@cugb.edu.cn
}

Received 15 February 2021; Revised 15 March 2021; Accepted 7 April 2021; Published 22 April 2021

Academic Editor: Pin Jia

Copyright (C) 2021 Hongfei Ma et al. This is an open access article distributed under the Creative Commons Attribution License, which permits unrestricted use, distribution, and reproduction in any medium, provided the original work is properly cited.

\begin{abstract}
The volume fracturing technique has been widely used to improve the productivity of ultralow-permeability reservoirs. This paper presents a new semianalytical model to simulate the pressure transient and production behaviour of finite conductivity vertical fractured wells with stimulated reservoir volume (SRV) in heterogeneous reservoirs. The model is based on the five-linear flow model, the Warren-Root model, and fracture conductivity influence function. The model is validated by comparing its results with a numerical model. One novelty of this model is its consideration of three different kinds of production prediction models. Constant rate, constant pressure, and compound working systems are taken into account. This paper illustrates the effects of the SRV size and shape, mobility ratio, initial flow rate, limiting wellbore pressure, and hydraulic fracture parameters under different working systems. Results show that the SRV and parameters of fractures have a significant influence on long-term well performance. Moreover, the initial rate can extend the constant rate period by $418 \%$, and limiting wellbore pressure can effectively improve the cumulative recovery rate by $23 \%$. Therefore, this model can predict long-term wells' behaviour and provide practical guiding significance for hydraulic fracturing design.
\end{abstract}

\section{Introduction}

With the increasing demand of the energy market and the incredible processing of hydraulic fracturing technology, the development of ultralow-permeability oil and gas reservoirs becomes increasingly critical. The hydraulic fracturing technique has been widely used to improve the productivity of tight reservoirs. Induced fractures will generate around hydraulic fractures, and the stimulated reservoir volume (SRV) will reduce the seepage resistance, change the flow model, and increase single well production [1]. However, the problems of unsteady flow caused by vertical fractures with finite conductivity are very complicated. It is usually necessary to deal with the coupled integral equation of formation flow and fracture flow. The compound linear flow model can avoid this problem and get an approximate solution, especially for the closed reservoir of narrow channel type.
Gringarten et al. [2] studied the pressure distribution of vertically fractured wells with infinite fracture conductivity in infinite homogeneous reservoirs, ignoring the influence of finite conductivity fractures. Lee and Brockenbrough [3] further developed an approximate solution for the trilinear flow of finite conductivity vertical fractured wells in infinite homogeneous reservoirs. Cinco et al. [4-7] simplified the trilinear flow model to the bilinear flow model, suitable for finite conductivity fractures in dual-porosity reservoirs. Houze et al. [8] introduced a solution for a reservoir with a fracture in a dual-porosity reservoir, which applies to the uniform flux and the infinite conductivity fracture. Brown et al. [9] proposed a new trilinear flow model where the SRV region was modelled by the Warren-Root [10] and Kazemi [11] models, but the enhanced region occupies the whole space between the fractures. Du et al. [12] described the SRV area based on Kazemi's dual-porosity medium model. Brohi et al. [13] proposed an analytical trilinear flow model 
to describe the system's pressure distribution. The SRV region occupies the entire space near the fractures in a heterogeneous reservoir. Stalgorova and Mattar [14, 15] improved the trilinear flow model to a five-region flow by simplifying the SRV into an enhanced area with limited width. However, the effect of the dual-porosity medium has not been considered. In recent years, Liu et al. $[16,17]$ used the fractal permeability composite reservoir model to evaluate tight reservoir productivity. Wang et al. [18] presented a semianalytical model by only taking the hydraulic fractures and SRV into account. Yuan et al. [19] proposed a new analytical solution model to evaluate the transient linear flow in heterogeneous reservoirs. However, few studies consider the production behaviour of finite conductivity vertical fractured wells with SRV in heterogeneous reservoirs despite the immense research efforts.

In recent years, there has been an increasing amount of literature on finite conductivity fractures. Al-Kobaisi et al. [20] employed a numerical method to obtain the pressure dynamics of finite conductivity fractures. However, the solutions are complex and need a large amount of computation unfavourable for wide application. Blasingame and Poe [21] regarded fracture conductivity as a kind of skin that can cause an extra pressure drop and so proposed the hybrid solution of a trilinear flow model (equivalent to the finite conductivity function) and an infinite conductivity model. This, however, is challenging to simulate the formation linear flow stage of finite conductivity fracture transits from bilinear flow to pseudoradial flow. Wilkinsons [22] solved the early flow characteristic function (fracture linear flow and bilinear flow) of low conductivity fractures by employing the Fourier transform method to deal with this problem. Wang et al. [23] gave the conductivity influence function in the Laplace domain, which simplified the calculation and was well applied. Based on the research results of Wang et al. [24], Wang et al. [25] calculated the semianalytical pressure solution of finite conductivity fracture by using the boundary element numerical method (BEM) and gave the finite conductivity influence function of quasi-steady state by data regression. Wang et al. [26] calculated the productivity of horizontal gas wells based on the finite conductivity function. Luo et al. [27] made a detailed analysis of the application range and calculation error of the conductivity influence function, but it was calculated in the Laplace domain. In this paper, an improved conductivity influence function in the time domain is derived for studying the hydraulic fracture behaviour, which possesses a higher degree of accuracy and can be easily applied.

The object of this paper is to establish a semianalytical model of ultralow-permeability reservoir with SRV. The reservoir is divided into several subsystems. The SRV region will be represented by Warren-Root dual-porosity model. The flow in the hydraulic fractures is calculated by the conductivity influence function. Expressions for both the bottom hole pressure function and rate function in the Laplace domain will be provided. The influence of sensitive parameters, such as the SRV size and shape, the permeability of SRV region, fracture conductivity, initial flow rate, and conversion pressure, is analysed under three different working systems, including the compound system, the constant flow rate system, and the constant flowing pressure system.

The compound working system developed in this work possesses a high degree of accuracy and enables long-term well performance prediction to be made quickly. The compound working system implies that production begins at a constant flow rate, and then, the production rate drops as well produces against constant pressure [28]. Numerous mathematical models have been adopted to investigate the flow in a single working system. However, the oilfield's actual production is usually under compound working system, and the dynamic model under a single working system cannot correctly predict well's production performance.

\section{Physical Model and Mathematical Model}

2.1. Physical Model. The fracture network formation near the wellbore is mainly related to reservoir pressure, mechanical rock properties, and natural fractures. The weak structural surfaces between rocks cause volume fractures such as natural fractures, joints, and bedding or weak points in the formation. Furthermore, the rock brittleness index is the physical property basis for forming a fracture network. Modern hydraulic fracturing technology can form a particular enhanced region with induced fractures near hydraulic fractures by controlling the injection and reverse discharge flow [29]. In this way, the near-wellbore zone is a fracture network formed by the interweaving of primary fractures and multistage secondary fractures. The area of the secondary fracture is also known as the stimulated reservoir volume (SRV). The SRV region is simulated through a Warren-Root dualporosity medium model.

Figure 1 shows the schematic diagram of the five-linear flow physical model. In the centre of a closed rectangular drainage area, there is a production well with hydraulic fractures that vertically penetrate through the reservoir. Only a quarter of the flow area will be considered because of the symmetry of the formation. The flow areas are divided into Regions 1, 2, 3, 4, and 5. Flow in the model is regarded as a combination of five linear flows within contiguous regions. Each region comprises one-dimensional linear flow, and the boundaries between regions are continuous in flux and pressure. To keep the solution general, each region has various parameters (permeability, porosity, and total compressibility). Region 4 represents the SRV region near the hydraulic fracture, while Region 5 represents the finite conductivity hydraulic fractures.

The basic assumptions of the model are as follows:

(i) The hydraulic fracturing vertical well is located in the centre of a rectangular low permeability oil reservoir with closed boundaries

(ii) The thickness of the reservoir is $h$, and the uniform initial pressure is $p_{\mathrm{i}}$

(iii) The hydraulic fractures thoroughly penetrate the formation 


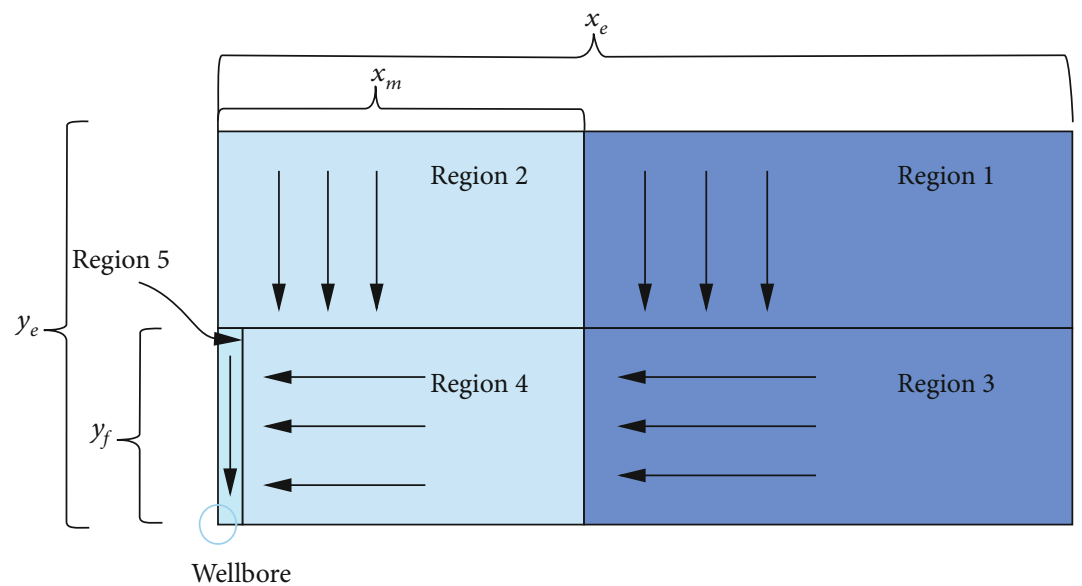

(a)

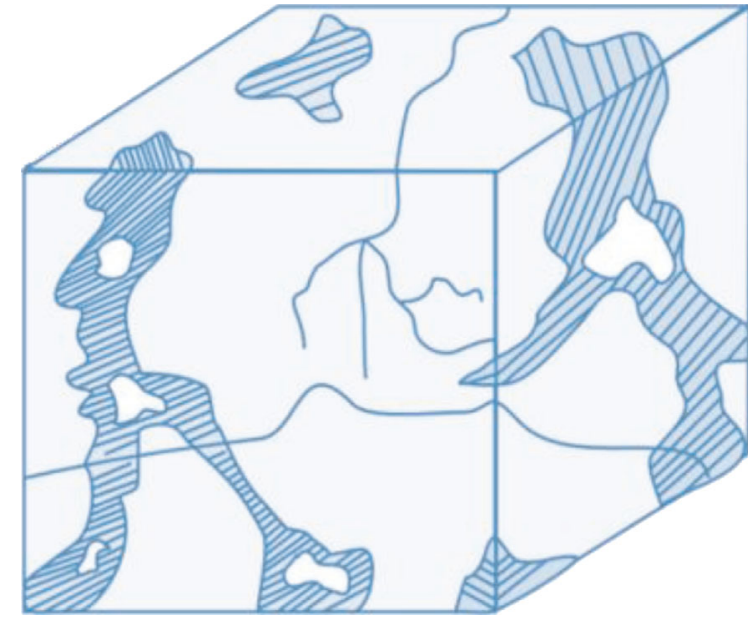

(b)

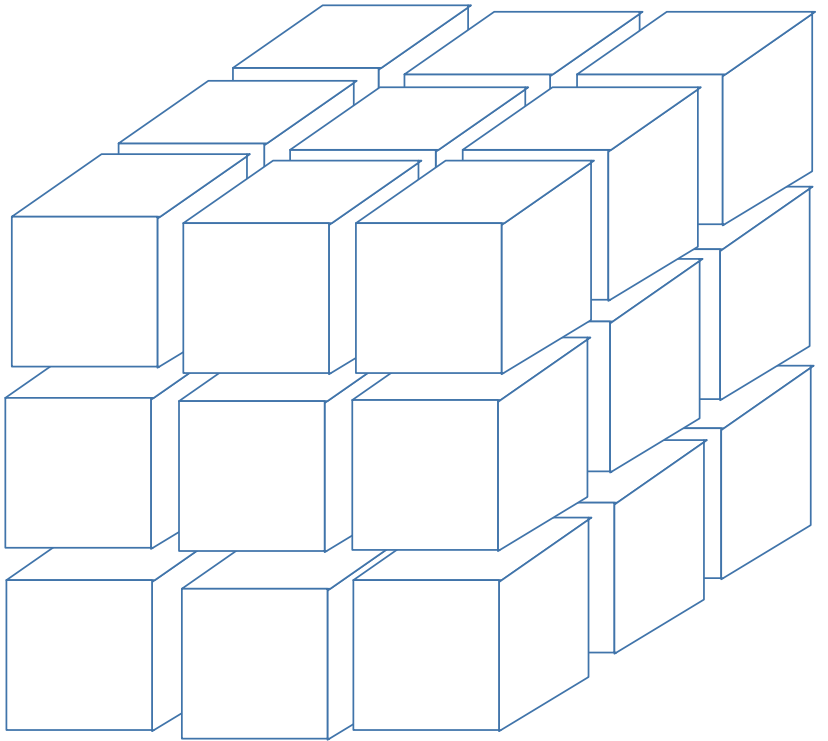

(c)

FIGURE 1: (a) Schematic of the five-linear flow model representing five continuous flow regions for a vertical well with an SRV region. (b) The matrix of SRV regions. (c) Classic Warren-Root dual-porosity medium model.

(iv) The effect of gravity and capillary forces on fluid flow in each region is negligible

(v) Isothermal single-phase fluid flow is assumed

2.2. Mathematical Model. The pressure distribution in each region is controlled by the flow equation given by

$$
\nabla^{2} p=\frac{\phi \mu c}{k} \frac{\partial p}{\partial t}
$$

To simplify the solution, this equation for each region was rewritten in dimensionless terms. The definitions of dimensionless parameters are given in Appendix A, and the derivations of equations and solutions are given in Appendix B.

2.2.1. Governing Equations in Region 1. Region 1 produces one-dimensional flow in the $y$-direction. This visualization of the flow behaviour is reasonable for fluid flow before the pseudo-steady-state flow period. Considering the symmetry, the flow governing differential equations and boundary conditions are as follows:

$$
\begin{gathered}
\frac{\partial^{2} p_{1 D}}{\partial y_{D}^{2}}=\frac{1}{\eta_{1 D}} \frac{\partial p_{1 D}}{\partial t_{D}}, \\
x_{w D}+x_{m D} \leq x_{D} \leq x_{e D}, \\
y_{w D}+1 \leq y_{D} \leq y_{e D} .
\end{gathered}
$$

The initial condition is

$$
p_{1 D}\left(x_{D}, y_{D}, 0\right)=0
$$

The outer boundary condition is

$$
\frac{\partial p_{1 D}\left(x_{D}, y_{e D}, t_{D}\right)}{\partial y_{D}}=0
$$


The interface conditions of Regions 1 and 3 are

$$
\begin{gathered}
p_{1 D}\left(x_{D}, y_{w D}+1, t_{D}\right)=p_{3 D}\left(x_{D}, y_{w D}+1, t_{D}\right), \\
\frac{\partial p_{1 D}\left(x_{D}, y_{w D}+1, t_{D}\right)}{\partial y_{D}}=\frac{\partial p_{3 D}\left(x_{D}, y_{w D}+1, t_{D}\right)}{\partial y_{D}} .
\end{gathered}
$$

2.2.2. Governing Equations in Region 2. In Region 2, the flow is assumed to be one-dimensional and in the $y$-direction. Considering the symmetry, the dimensionless governing equations are as follows $\left(x_{w m D}=x_{w D}+x_{m D}\right)$ :

$$
\begin{gathered}
\frac{\partial^{2} p_{2 D}}{\partial y_{D}^{2}}=\frac{1}{\eta_{2 D}} \frac{\partial p_{2 D}}{\partial t_{D}}, \\
x_{w D} \leq x_{D} \leq x_{w m D}, \\
y_{w D}+1 \leq y_{D} \leq y_{e D} .
\end{gathered}
$$

The initial condition is

$$
p_{2 D}\left(x_{D}, y_{D}, 0\right)=0 \text {. }
$$

The outer boundary condition is

$$
\frac{\partial p_{2 D}\left(x_{D}, y_{e D}, t_{D}\right)}{\partial y_{D}}=0 .
$$

The interface conditions of Regions 2 and 4 are as follows:

$$
\begin{gathered}
p_{1 D}\left(x_{D}, y_{w D}+1, t_{D}\right)=p_{3 D}\left(x_{D}, y_{w D}+1, t_{D}\right), \\
\frac{\partial p_{1 D}\left(x_{D}, y_{w D}+1, t_{D}\right)}{\partial y_{D}}=\frac{\partial p_{3 D}\left(x_{D}, y_{w D}+1, t_{D}\right)}{\partial y_{D}} .
\end{gathered}
$$

2.2.3. Governing Equations in Region 3. In Region 3, the onedimensional flow in the $x$-direction is dominant. Take the integral average along the $y$-direction in Region 3. The flow is simplified as a linear flow perpendicular to the hydraulic fracture plane given by

$$
\frac{\partial^{2} p_{3 D}}{\partial x_{D}^{2}}+\int_{y_{w D}}^{y_{w D}+1} \frac{\partial}{\partial y_{D}}\left(\frac{\partial p_{D}}{\partial y_{D}}\right) d \alpha=\frac{1}{\eta_{3 D}} \frac{\partial p_{3 D}}{\partial t_{D}}
$$

Since the normal plane of the centre of the hydraulic fracture plane has distributivity, combined with Equation (5), a partial differential equation can be attained as follows:

$$
\frac{\partial^{2} p_{3 D}}{\partial x_{D}^{2}}+\frac{\partial p_{1 D}\left(y_{w D}+1, t_{D}\right)}{\partial y_{D}}=\frac{1}{\eta_{3 D}} \frac{\partial p_{3 D}}{\partial t_{D}}
$$

The initial condition is

$$
p_{3 D}\left(x_{D}, y_{D}, 0\right)=0
$$

The outer boundary condition is

$$
\frac{\partial p_{3 D}\left(x_{e D}, y_{D}, t_{D}\right)}{\partial x_{D}}=0
$$

The interface conditions of Regions 3 and 4 are as follows:

$$
\begin{gathered}
p_{3 D}\left(x_{w m D}, y_{D}, t_{D}\right)=p_{4 D}\left(x_{w m D}, y_{D}, t_{D}\right) \\
\frac{k}{\mu} \frac{\partial p_{3 D}\left(x_{w m D}, y_{w D}, t_{D}\right)}{\partial x_{D}}=\frac{k_{4}}{\mu} \frac{\partial p_{m D}\left(x_{w m D}, y_{w D}, t_{D}\right)}{\partial x_{D}} .
\end{gathered}
$$

2.2.4. Governing Equations in Region 4. In Region 4, the matrix's permeability is much lower than that of fracture, so the pressure drop rate is slower. There is a pressure difference between the matrix and the fracture, resulting in crossflow. According to the law of conservation of mass, Darcy law, and the classical Warren-Root model, SRV region's flow is assumed to be one-dimensional and in the $x$-direction perpendicular to the hydraulic fracture plane. The associated equations are given by

$\frac{\partial^{2} p_{4 f D}}{\partial x_{D}^{2}}+\frac{1}{y_{e D} C_{R D}} \frac{\partial p_{2 D}\left(y_{w D}+1, s\right)}{\partial y_{D}}+\lambda\left(p_{4 m D}-p_{4 f D}\right)=\omega \frac{\partial p_{4 f D}}{\partial t_{D}}$

$$
\lambda\left(p_{4 m D}-p_{4 f D}\right)=(1-\omega) \frac{\partial p_{4 m D}}{\partial t_{D}} .
$$

The initial condition is

$$
p_{4 m D}\left(x_{D}, y_{D}, 0\right)=p_{4 f D}\left(x_{D}, y_{D}, 0\right)=0 \text {. }
$$

The inner boundary condition is

$$
\left.\frac{\partial p_{4 f D}\left(x_{w D}, t_{D}\right)}{\partial x_{D}}=-\frac{\pi}{2} \text { (constant rate }\right)
$$

2.3. Model Solution. We derive the solutions for Regions 1, 2, and 3 and the SRV region and then couple the solutions by using the flux and pressure continuity conditions on the interfaces between regions. The detailed derivation of the 
preceding equations with boundary conditions is provided in Appendix B.

$$
\begin{aligned}
s p_{w D}^{\tilde{\inf }}(0, s) & =\frac{\pi}{2} \cdot \frac{1}{\sqrt{C_{2}(s)}} \cdot \frac{1+k_{D} \sqrt{\left(C_{1}(s) / C_{2}(s)\right)} \tanh \left[x_{m D} \sqrt{C_{2}(s)}\right] \tanh \left[\left(x_{e D}-x_{w m D}\right) \sqrt{C_{1}(s)}\right]}{\tanh \left[x_{m D} \sqrt{C_{2}(s)}\right]+k_{D} \sqrt{\left(C_{1}(s) / C_{2}(s)\right)} \tanh \left[\left(x_{e D}-x_{w m D}\right) \sqrt{C_{1}(s)}\right]}, \\
C_{1}(s) & =\frac{s}{\eta_{3 D}}+\sqrt{\frac{s}{\eta_{3 D}}} \tanh \left[\left(y_{e D}-y_{w D}-1\right) \sqrt{\frac{s}{\eta_{3 D}}}\right] \\
C_{2}(s) & =u(s)+k_{D} \sqrt{\frac{s}{\eta_{2 D}}} \cdot \tanh \left[\left(y_{e D}-y_{w D}-1\right) \sqrt{\frac{s}{\eta_{2 D}}}\right] .
\end{aligned}
$$

According to the convolution theorem, the wellbore flow rate under constant pressure is

$$
s \tilde{q}_{w D}(s)=\frac{2 \sqrt{C_{2}(s)}}{\pi} \frac{\tan \mathrm{h}\left[x_{m D} \sqrt{C_{2}(s)}\right]+k_{D} \sqrt{\left(C_{1}(s) / C_{2}(s)\right)} \tan \mathrm{h}\left[\left(x_{e D}-x_{w m D}\right) \sqrt{C_{1}(s)}\right]}{1+k_{D} \sqrt{\left(C_{1}(s) / C_{2}(s)\right)} \tan \mathrm{h}\left[x_{m D} \sqrt{C_{2}(s)}\right] \tan \mathrm{h}\left[\left(x_{e D}-x_{w m D}\right) \sqrt{C_{1}(s)}\right]} .
$$

This solution can be inverted from the Laplace to the time domain with the numerical algorithm given by Stehfest [30].

2.3.1. Conductivity Influence Function. Wilkinsons [22] placed the fracture in the formation with impermeable boundaries at its endpoint and analytically solved the early flow characteristic function of low conductivity fracture by the Fourier transform method. Based on the asymptotic fitting analysis method, the modified transformation is

$$
s \tilde{f}_{1}\left(c_{f D}\right)=\sum_{n=1}^{\infty} \frac{2 \pi}{n^{2} \pi^{2} c_{f D}+2 \sqrt{n^{2} \pi^{2}+s}} .
$$

Based on the numerical simulation results, the correction function $\Delta f^{\sim}\left(c_{f D}\right)$ is introduced to improve the accuracy of the hybrid solution to yield

$$
\begin{gathered}
\Delta \tilde{f}\left(c_{f D}\right)=\frac{\pi \Delta E}{\pi+\Delta E \cdot 4 s}, \\
\Delta \tilde{f}\left(c_{f D}\right) \approx \begin{cases}\Delta E & s \rightarrow 0, \\
\frac{\pi}{4 s} & s \rightarrow \infty,\end{cases} \\
\Delta E=\frac{\left(c_{1}\left(1 / c_{f D}\right)\right) c_{2}}{\left(c_{1}\left(1 / c_{f D}\right)\right)+c_{2}}, \quad c_{1}=\left[\frac{4(\pi-2)}{\pi}-\frac{\pi}{3}\right], c_{2}=\ln \frac{\pi}{2} .
\end{gathered}
$$

Finally, a more accurate solution at the wellbore is obtained as

$$
\tilde{s} p_{w D}(s)=s \tilde{s i n f}_{w D}(0, s)+s \tilde{f}_{1}\left(c_{f D}\right)+\Delta \tilde{f}\left(c_{f D}\right)
$$

At the same time, the pseudo-steady-state flow asymptotic analysis ( $s$ approaches 0 ) of Equation (25) is done, and the pseudo-steady-state expression of the finite conductivity function in the time domain can be written as follows:

$$
f\left(C_{f D}\right)=\sum_{n=1}^{\infty} \frac{2}{n\left(n \pi c_{f D}+2\right)}+\Delta E .
$$

Wang et al. [25] gave the finite conductivity factor in the pseudo-steady-state through progressive analysis and multiple regression methods as follows:

$f\left(C_{f D}\right)=\frac{0.95-0.56 \psi+0.16 \psi^{2}-0.028 \psi^{3}+0.0028 \psi^{4}-0.00011 \psi^{5}}{1+0.094 \psi+0.093 \psi^{2}+0.0084 \psi^{3}+0.001 \psi^{4}+0.00036 \psi^{5}}$,

where $\Psi=\ln \left(C_{f D}\right)$.

Equation (29) is a fitting function and has no specific physical meaning but can simplify the calculation. Comparing and analysing Equations (28) and (29), the results show that the two methods provide good fitting results when the value of fracture conductivity is greater than 0.0631 (see 
TABLE 1: Fracture conductivity influence function.

\begin{tabular}{lccccccc}
\hline$C_{f D}$ & $f\left(C_{f D}\right)$ Equation $(29)$ & $f\left(C_{f D}\right)$ & Relative error $(\%)$ & $C_{f D}$ & $f\left(C_{f D}\right)$ Equation $(29)$ & $f\left(C_{f D}\right)$ & Relative error $(\%)$ \\
\hline 0.01 & 7.8304 & 5.16526 & 51.5974 & 0.31623 & 1.84865 & 1.83579 & 0.7005 \\
0.01259 & 6.88014 & 4.93793 & 39.3325 & 0.39811 & 1.64816 & 1.63775 & 0.6356 \\
0.01585 & 6.12671 & 4.71057 & 30.0630 & 0.50119 & 1.4568 & 1.44818 & 1.26871 \\
0.01995 & 5.51179 & 4.48325 & 22.9418 & 0.63096 & 1.27575 & 0.5952 \\
0.02512 & 4.9974 & 4.25607 & 17.4182 & 0.79433 & 1.10638 & 1.10089 & 0.4987 \\
0.03162 & 4.55765 & 4.02915 & 13.1169 & 2 & 0.56609 & 0.56731 & -0.2150 \\
0.03981 & 4.17424 & 3.80263 & 9.7724 & 3 & 0.4026 & 0.40658 & -0.9789 \\
0.05012 & 3.83381 & 3.57667 & 7.1894 & 4 & 0.31141 & 0.31707 & -1.7851 \\
0.0631 & 3.52637 & 3.35151 & 5.2173 & 5 & 0.25319 & 0.25993 & -2.5930 \\
0.07943 & 3.24435 & 3.12743 & 3.7385 & 6 & 0.21278 & 0.22025 & -3.3916 \\
0.1 & 2.98195 & 2.9048 & 2.6559 & 7 & 0.18312 & 0.19109 \\
0.12589 & 2.73478 & 2.68411 & 1.8878 & 8 & 0.16043 & 0.16875 \\
0.15849 & 2.49962 & 2.46598 & 1.3642 & 9 & 0.14253 & 0.15109 & -4.1708 \\
0.19953 & 2.27427 & 2.25119 & 1.0252 & 10 & 0.12805 & 0.13676 & -5.9304 \\
0.25119 & 2.05743 & 2.04072 & 0.8188 & & & -6.3688 & \\
\hline
\end{tabular}

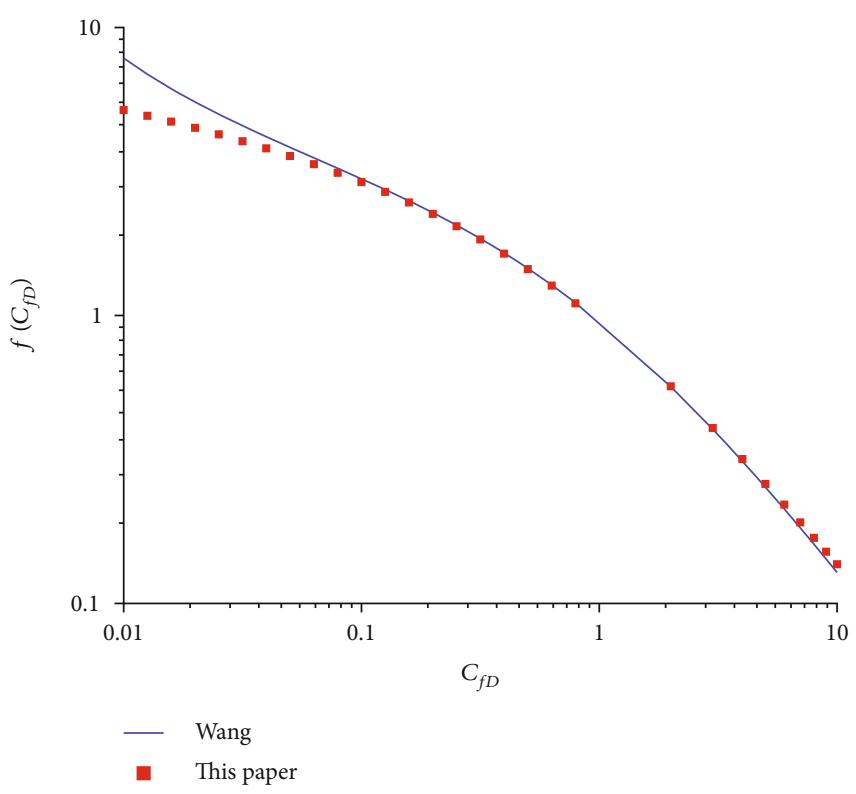

Figure 2: A validation analysis of the finite conductivity function.

Table 1 and Figure 2), indicating that this paper's finite conductivity factor is reliable.

It deserves noting that when the SRV (Region 4) occupies all the space between fractures and boundaries, the fiveregion model is simplified to the trilinear model of Brown et al. [9]. When the contributions of Regions 1 and 2 are neglected, the five-region model reduces to the enhanced fracture region model of Stalgorova and Mattar [13]. For this reason, the five-region model is a generalization that covers both the five-linear model and Warren-Root model.

\subsection{Possible Model Modifications}

2.4.1. Gas Flow. This model was derived for an oil system. However, it can also be applied to gas flow. It should be
TABLE 2: Model parameters.

\begin{tabular}{lcc}
\hline Parameters & Symbol & Value \\
\hline Initial pressure $(\mathrm{MPa})$ & $p_{\mathrm{i}}$ & 28.5 \\
Reservoir length $(\mathrm{m})$ & $x_{e}$ & 1500 \\
Reservoir width $(\mathrm{m})$ & $y_{e}$ & 300 \\
Oil viscosity $(\mathrm{mPa} \cdot \mathrm{s})$ & $\mu_{o}$ & 8 \\
Oil volume factor $\left(\mathrm{m}^{3} / \mathrm{m}^{3}\right)$ & $B_{o}$ & 1.2 \\
Porosity & $\varphi$ & 0.2 \\
Formation permeability $(\mathrm{mD})$ & $k$ & 3 \\
SRV region permeability $(\mathrm{mD})$ & $k_{4}$ & 80 \\
Fracture half-length $(\mathrm{m})$ & $y_{f}$ & 50 \\
SRV region width $(\mathrm{m})$ & $2 x_{4}$ & 150 \\
Reservoir compressibility $\left(\mathrm{MPa}^{-1}\right)$ & $c$ & 0.00373 \\
\hline
\end{tabular}

noted that the diffusivity term, $\eta$, is not constant but varies with pressure. Therefore, the gas reservoir time should be expressed in terms of pseudotime, and the pressure should be handled through a pseudopressure transformation $[14,15,31]$.

$$
\begin{aligned}
m(p) & =2 \int_{p_{\text {ref }}}^{p} \frac{\xi}{\mu(\xi) z(\xi)} d \xi \\
t_{a} & =\int_{0}^{t} \frac{\mu_{g i} c_{g i}}{\mu(\xi) c(\xi)} d \xi
\end{aligned}
$$

2.4.2. Wellbore Storage. According to the recommendations of Brown et al. [9], wellbore storage effects can also be included. To consider wellbore storage, the wellbore pressure given in Equation (22) can be modified to 


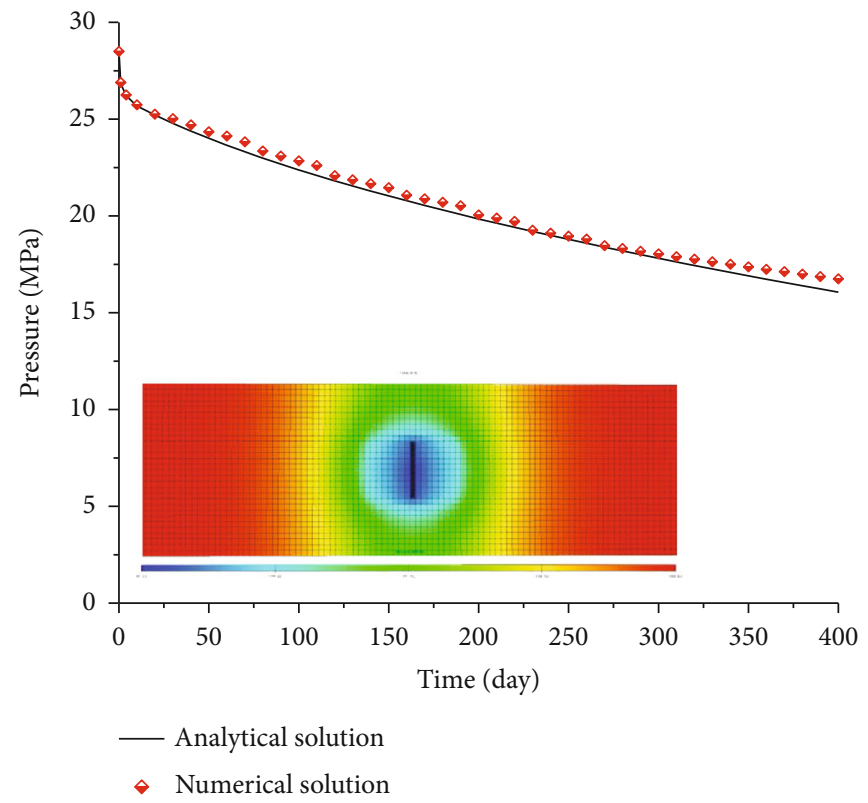

(a)

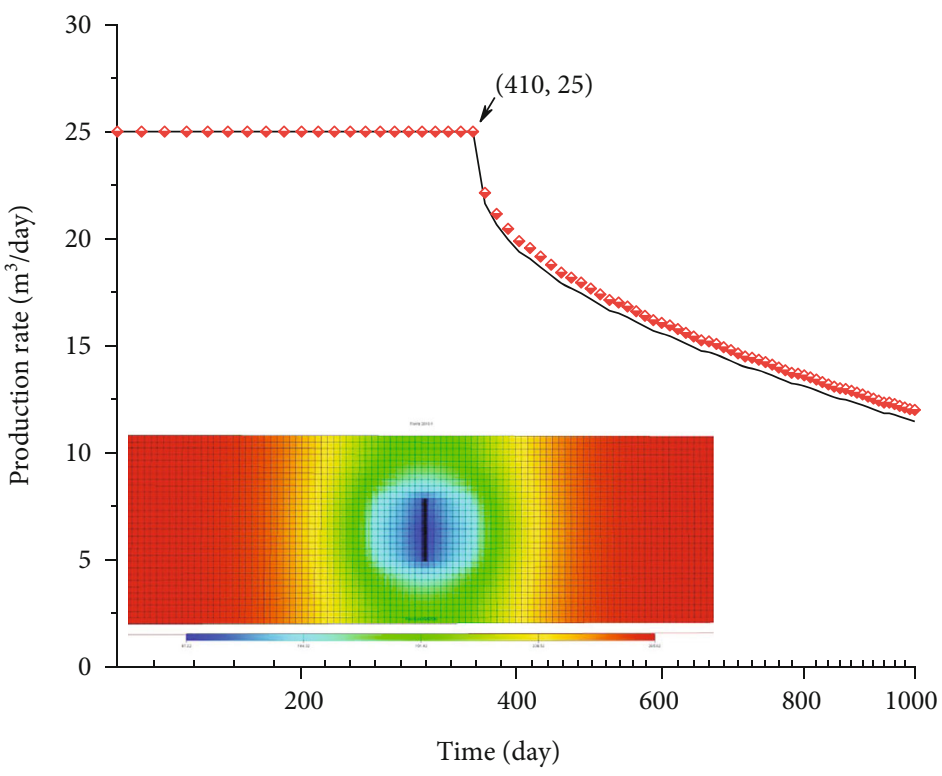

- Analytical Solution

$\diamond$ Numerical Solution

(b)

Figure 3: (a) Comparing analytical and numerical solutions in the constant rate system. (b) Comparing analytical and numerical solutions in the compound working system.

$$
\tilde{p}_{w D, \text { storage }}=\frac{\tilde{p}_{w D}}{1+C_{f D} s^{2} \tilde{p}_{w D}} .
$$

2.5. Model Validation. To validate the developed model, comparisons between the analytical and numerical simulation results under different working systems were conducted. Isothermal single-phase fluid flow is assumed. The different working systems include the constant flow rate system and compound system. The semianalytical model is inverted with the Stehfest algorithm [30]. For numerical simulation, the $2 \mathrm{D}$ finite-difference method is used to simulate flow in the reservoir. The formation was modeled with $150 \times 30$ grid cells. A local grid fine area around the hydraulic fracture was defined to ensure the difference in model's accuracy. The reservoir parameters and well parameters are shown in Table 2. The numerical and analytical solution results are shown in Figure 3. For these parameters, the numerical and analytical solutions in the different working systems are in excellent 


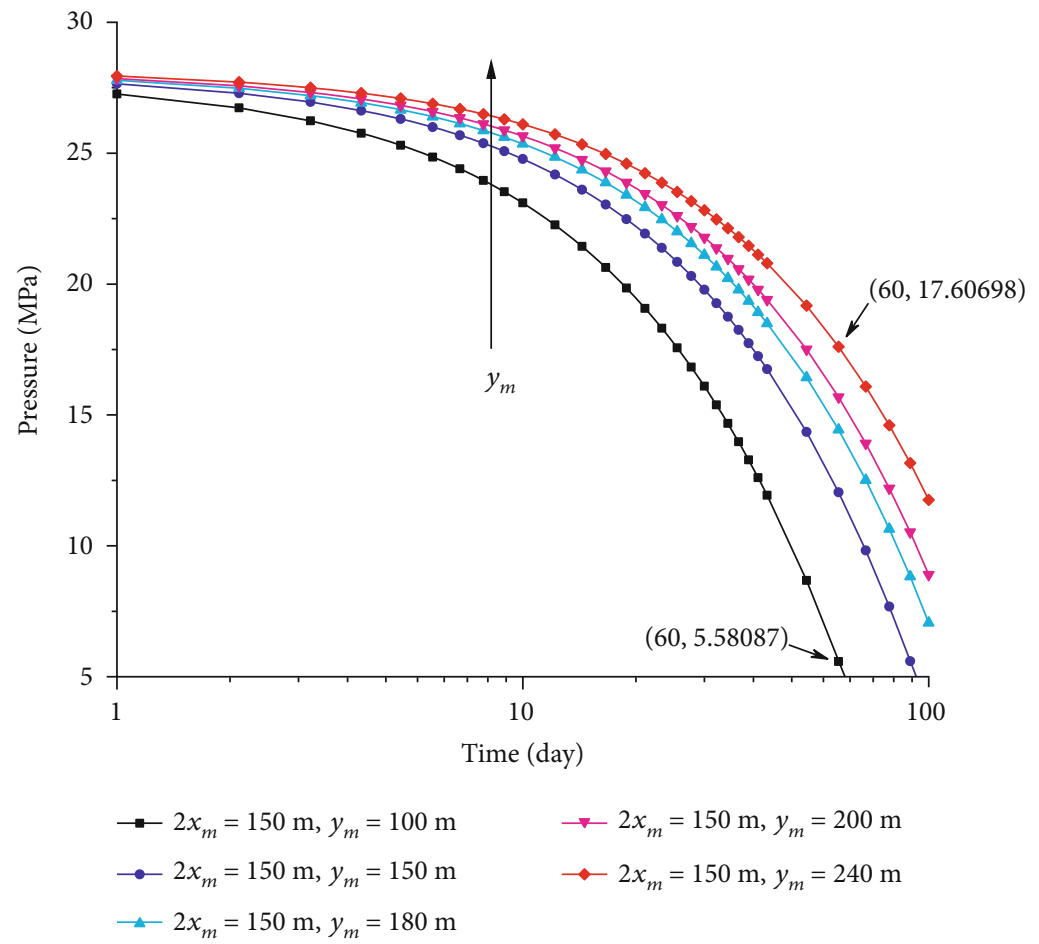

FIGURE 4: The effect of SRV size on the curves (constant rate).

agreement. Minor divergences are believed because numerical simulator has more considerations. Therefore, the semianalytical model can be applied to predict long-term well performance.

\section{Results and Discussion}

Sensitivity studies illustrate the essential parameters affecting oil production performance. The parameters discussed include the SRV size and shape, fracture conductivity, mobility ratio, initial flowing rate, and limiting wellbore pressure under different working systems. Constant rate, constant pressure, and compound working systems are taken into account. Parameters for Regions 1, 2, and 3 can be considered identical for practical purposes. The most important influencing factors in the figures are displayed in a dimensional form to make the results intuitive.

\subsection{Constant Production Working System}

3.1.1. Shape and Size of Stimulated Reservoir Volume. Figures 4 and 5 show the effect of the SRV region's different sizes and shapes on the wellbore pressure. In Figure 4, the SRV length remains fixed at $150 \mathrm{~m}$, and the SRV width is varied $(100 \mathrm{~m}, 150 \mathrm{~m}, 180 \mathrm{~m}, 200 \mathrm{~m}$, and $240 \mathrm{~m})$. As the SRV area increases, the rate of pressure at the wellbore decline slows down by $54 \%$. This is mainly because, in the early stages, flow only occurs in the hydraulic fractures and the stimulated region near the well, which is not affected by the size of SRV. In the exploitation process, the production wave spreads to the SRV region edges, where reservoirs with larger effective SRVs have a lower pressure decline rate. Therefore, an appropriate SRV size should be ensured in the fracturing design.

Figure 5 (a) shows that the $x$-direction rectangular shape of the SRV results in a slower wellbore pressure decline rate. Figure 5(b) is the schematic diagram of five different SRV shapes, and the SRV size is fixed at $25600 \mathrm{~m}^{3}$. Under constant production, increasing the ratio of length to width can effectively slow down formation energy loss. In the production process, the production wave spreads to the edges of the SRV region, and unstimulated regions participate in the flow. Region 2 is the first and dominant region. When the shape of the enhanced region is similar to the formation, Region 2 has a more extensive scope and sufficient supply, resulting in better performance.

3.1.2. Fracture Conductivity and Mobility Ratio. The effect of fracture conductivity $\left(C_{f D}=0.01,0.1,1,10,125\right)$ under the condition of constant flow rate is shown in Figure 6. At the initial stage of production, the bottom hole flow pressure changes slowly, and the reservoir of energy loss is small. At the middle stage, the wellbore flow pressure decreases rapidly. When the fracture conductivity increases, the rate of wellbore pressure decline decreases by about $32 \%$. For fracture conductivities of 10 and above, pressures are the same. That is, for $C_{f D} \geq 10$, there is a pronounced reduction in formation energy loss.

The influence of mobility ratio between the enhanced area and matrix area on wellbore pressure is shown in Figure 7. Here, the SRV permeability of $k_{4}$ is varied while all other properties are kept constant. It can be seen that, as the value of mobility ratio increases, the rate of wellbore 


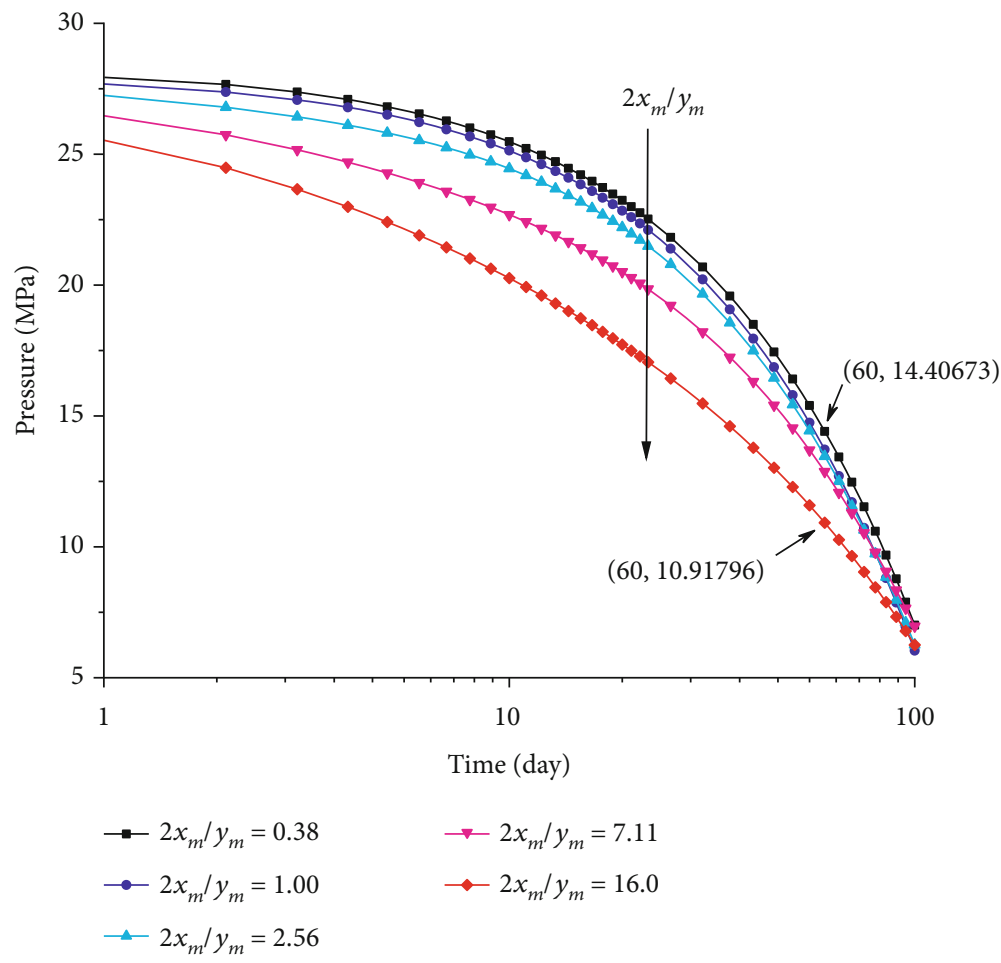

(a)

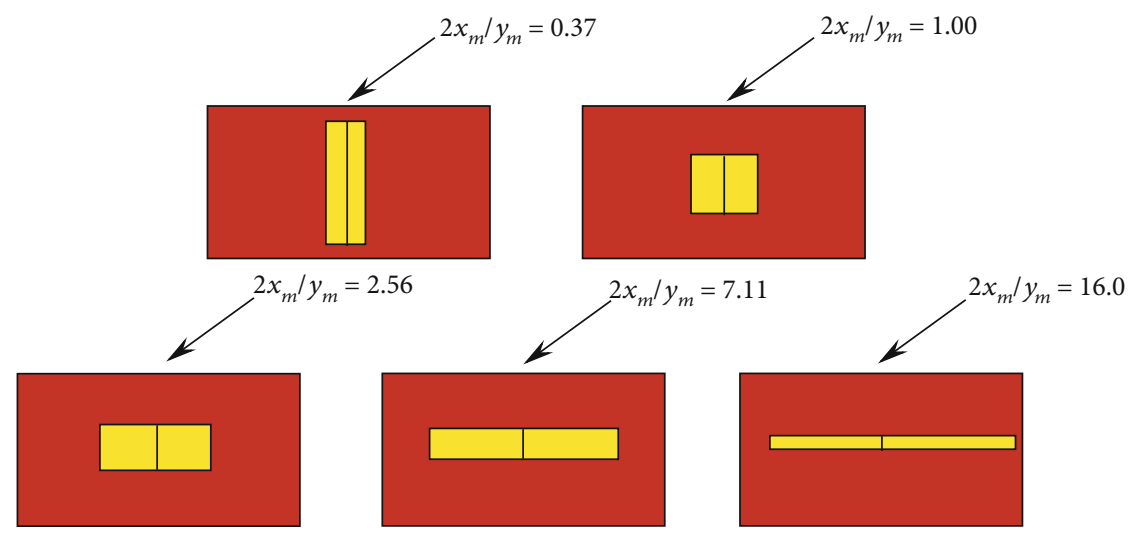

(b)

FIGURE 5: (a) The effect of SRV shape on the flow rate and cumulative yield. (b) Schematic diagram of five different SRV shapes (constant rate).

pressure decline slows down by $83.9 \%$. Since the matrix fluid supply capacity is sufficient and the enhanced SRV permeability helps with fluid flow, the wellbore pressure drops slowly as a result. Thus, it is essential to improve the SRV permeability in the fracturing design to extend the constant rate period.

\subsection{Constant Pressure Working System}

3.2.1. Shape and Size of Stimulated Reservoir Volume. Under a constant wellbore pressure, the effects of SRV size and shape on the production are shown in Figures 8 and 9. In Figure 8, the width of the SRV remains fixed and the length is varied $\left(y_{m}=20,40,100,180,240 \mathrm{~m}\right)$. When the fracture length is relatively small $\left(y_{m}<180 \mathrm{~m}\right)$, a larger SRV size leads to higher cumulative oil production. When the fracture length is increased, increasingly induced fractures in the SRV region become effectively connected with artificial hydraulic fractures, forming a larger supply area and improving the cumulative production. This, however, has little effect on the production when the width is greater than $180 \mathrm{~m}$ as a result of the reservoirs controlled by a single are very limited. Considering the cost and difficulty of fracturing factors, an appropriate fracturing length should be considered.

As shown in Figure 9, the enhanced area's volume is fixed at $256000 \mathrm{~m}^{3}$, while the length-width ratio of the stimulated area is varied $\left(x_{m} / y_{m}=0.38,0.64,1.00,2.56\right.$, and 7.11$)$. The schematic diagram of SRV shapes is displayed in Figure 5(b). Results show that an SRV rectangular shape along the $x$-direction enables higher production during the middle stage. In the production process, the production wave spreads to the edges of the SRV region. The unstimulated 


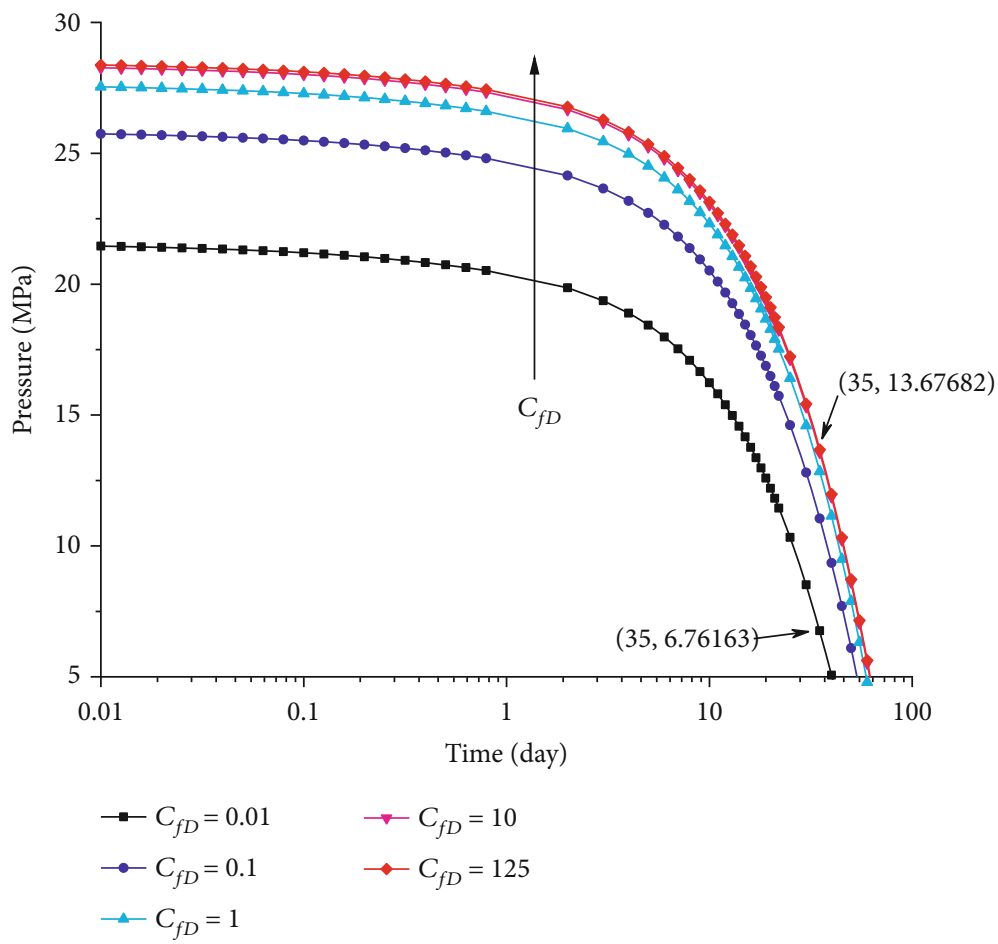

Figure 6: The effect of fracture conductivity on the wellbore pressure (constant rate).

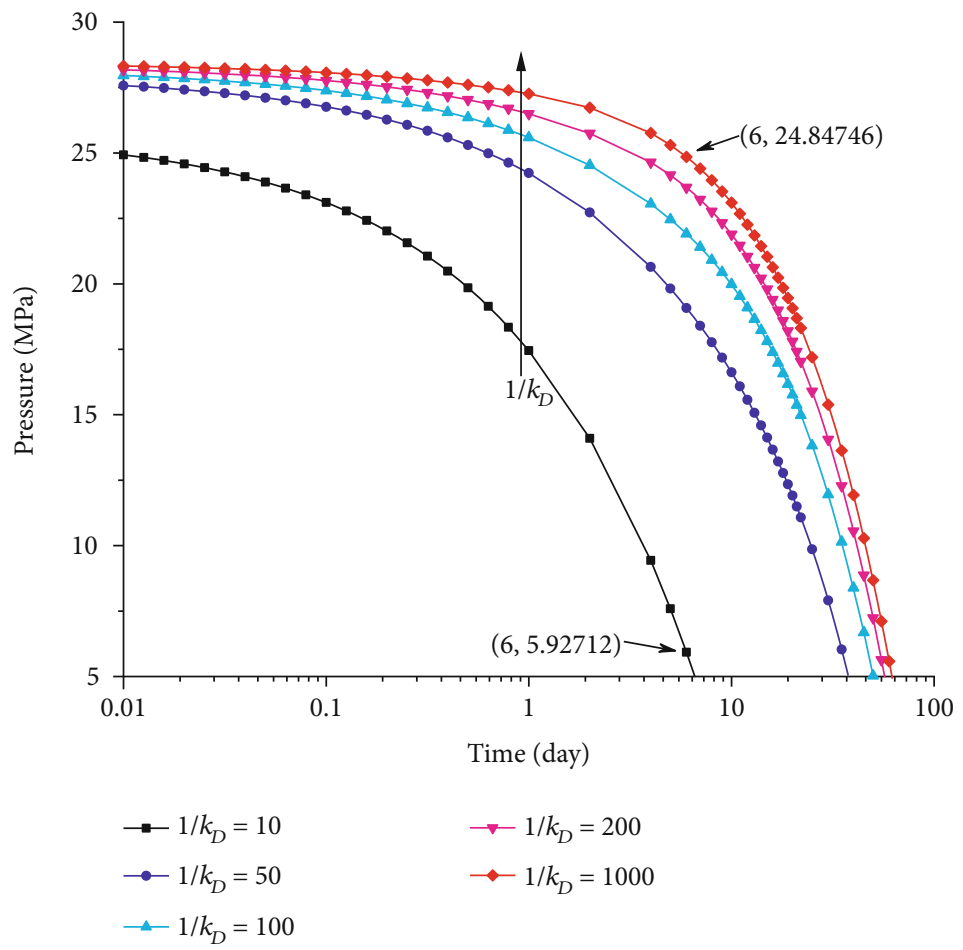

FIGURE 7: Effect of mobility ratio on the wellbore pressure (constant rate).

regions participate in the flow in which Region 2 is the first and dominant region. When the shape of the enhanced region is similar to the formation, Region 2 has a more extensive scope and sufficient supply, leading to improved performance.
3.2.2. Fracture Conductivity and Mobility Ratio. The effect of fracture conductivity $\left(C_{f D}=10,50,100,300,500\right)$ under the condition of constant pressure is shown in Figure 10. As can be seen, an increase in fracture conductivity can increase productivity by up to $814 \%$. The effect of hydraulic fractures 


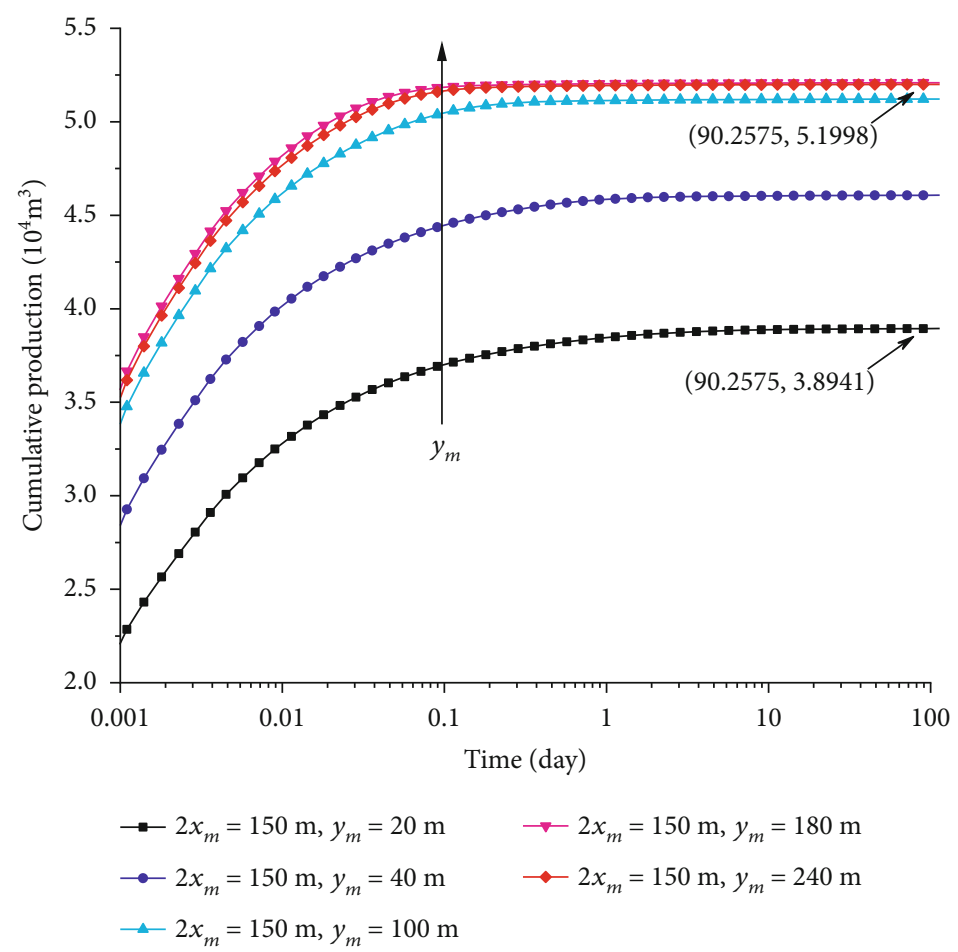

FIGURE 8: The effect of SRV size on cumulative production (constant pressure).

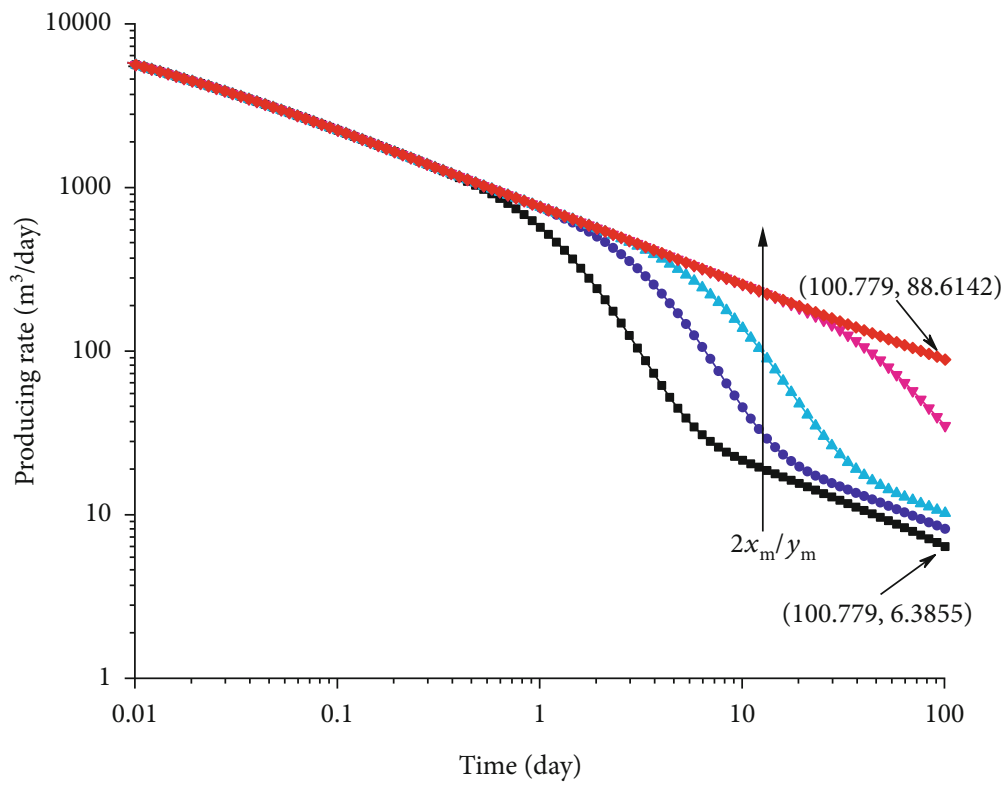

$$
\begin{array}{ll}
\rightarrow 2 x_{m} / y_{m}=0.38 & \rightarrow 2 x_{m} / y_{m}=2.56 \\
\rightarrow-2 x_{m} / y_{m}=0.64 & \rightarrow-2 x_{m} / y_{m}=7.11 \\
-2 x_{m} / y_{m}=1.00 &
\end{array}
$$

FIGURE 9: The effect of SRV shape on production (constant pressure).

is to create a high permeability channel near the wellbore formation, which is convenient for oil to flow from the far formation to the bottom hole. For $C_{f D}>300$, the cumulative production curves coincide, which means that hydraulic fractures can be regarded as uniform flow fractures.
Figure 11 represents the impact of the mobility ratio between the SRV region and other regions on the flow rate curves. In these scenarios, the formation permeability, $k$, is kept constant while the value of $k_{4}$ is varied to yield different mobility ratios. The larger the mobility ratio is, the more 


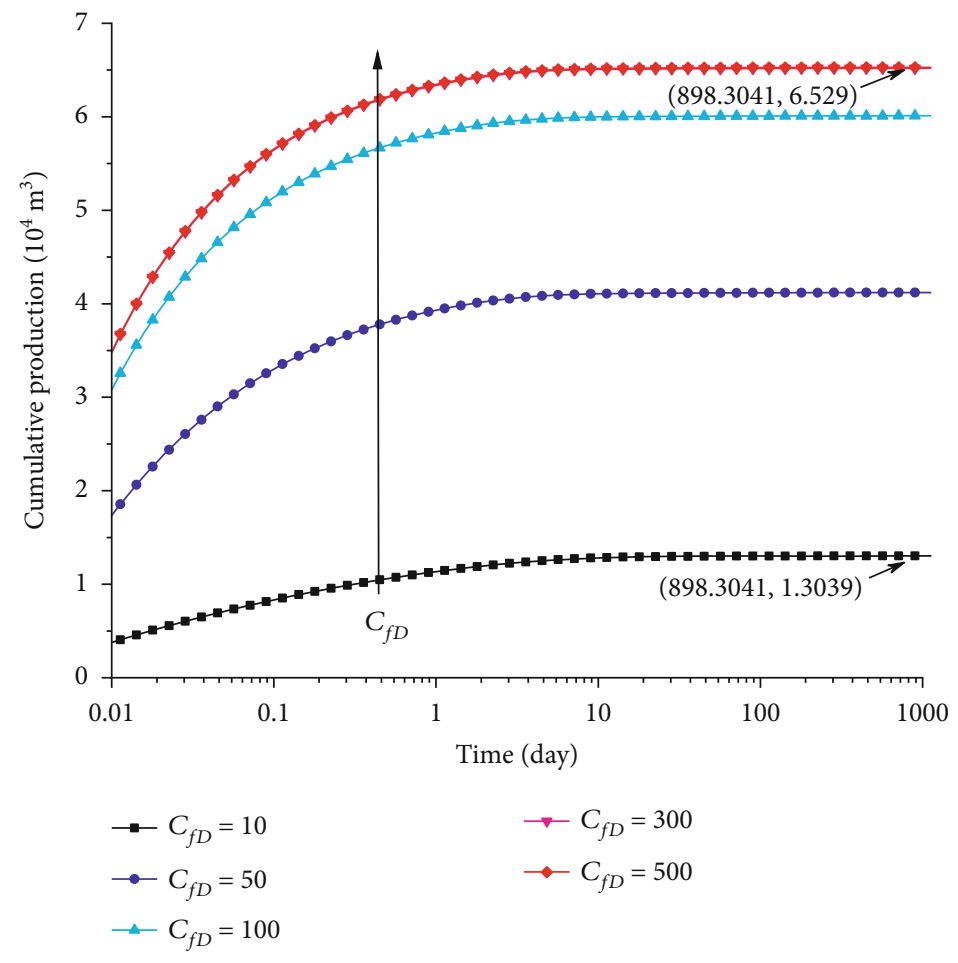

Figure 10: The effect of fracture conductivity on cumulative production (constant pressure).

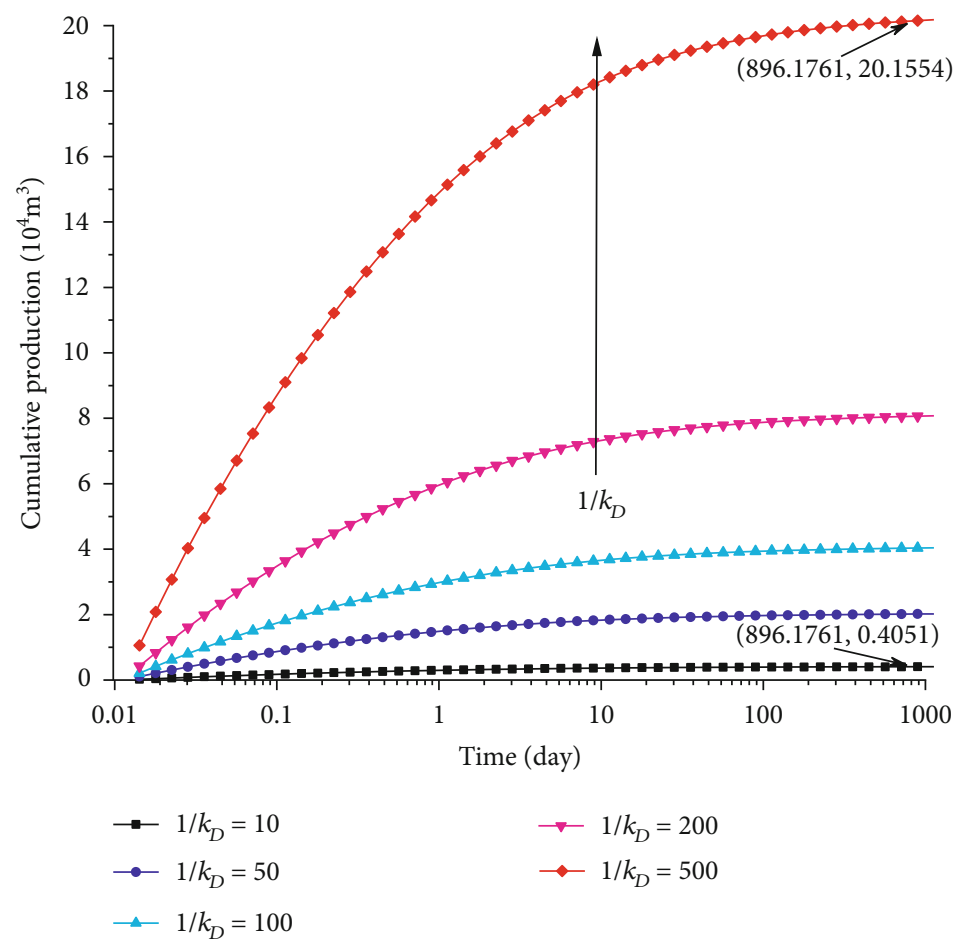

FIGURE 11: The effect of mobility ratio on cumulative production (constant pressure).

pronounced the stimulation effect. Due to the high permeability and strong fluid supply capacity of the formation in the enhanced area, the productivity is naturally higher.
3.3. Compound Working System. Under the compound working system, an oil well's production performance can be summarized in a chronological manner. In the first stage, 


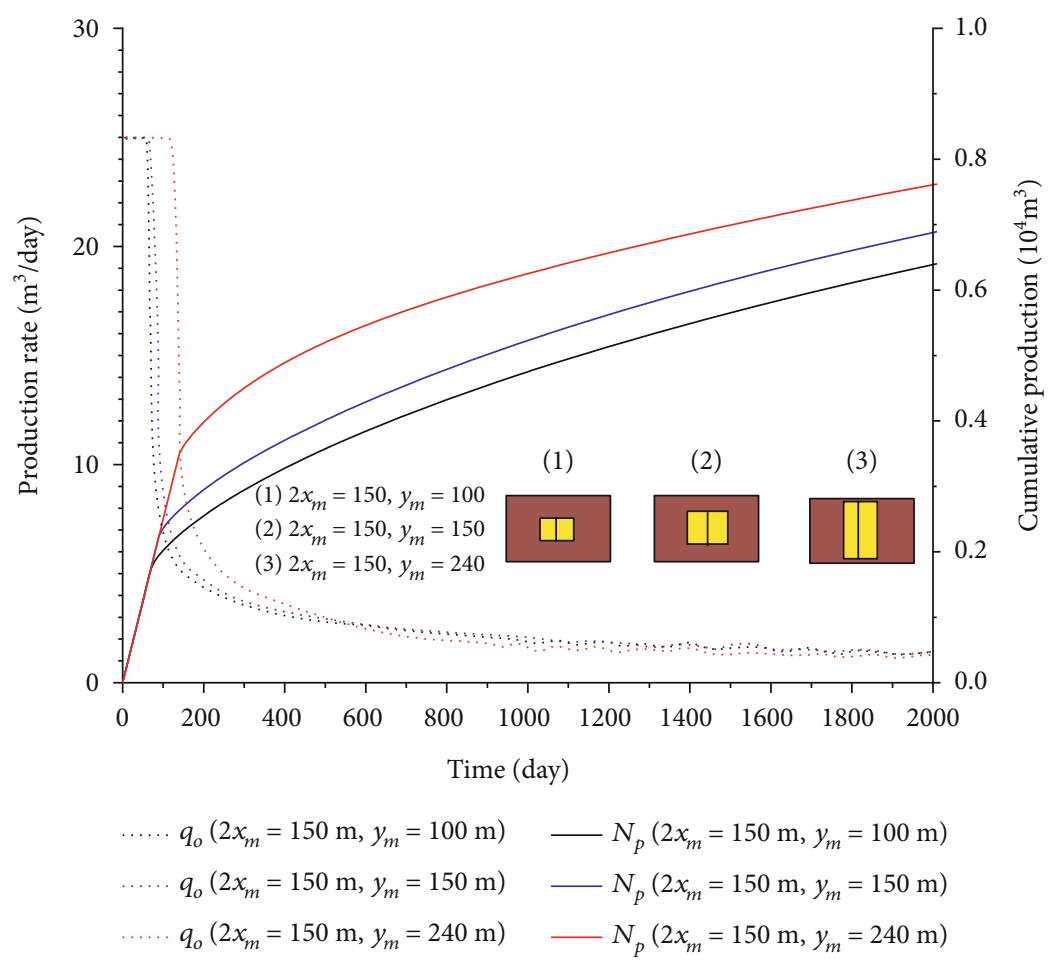

FIgURE 12: The effect of SRV size on the flow rate and cumulative yield (compound working system).

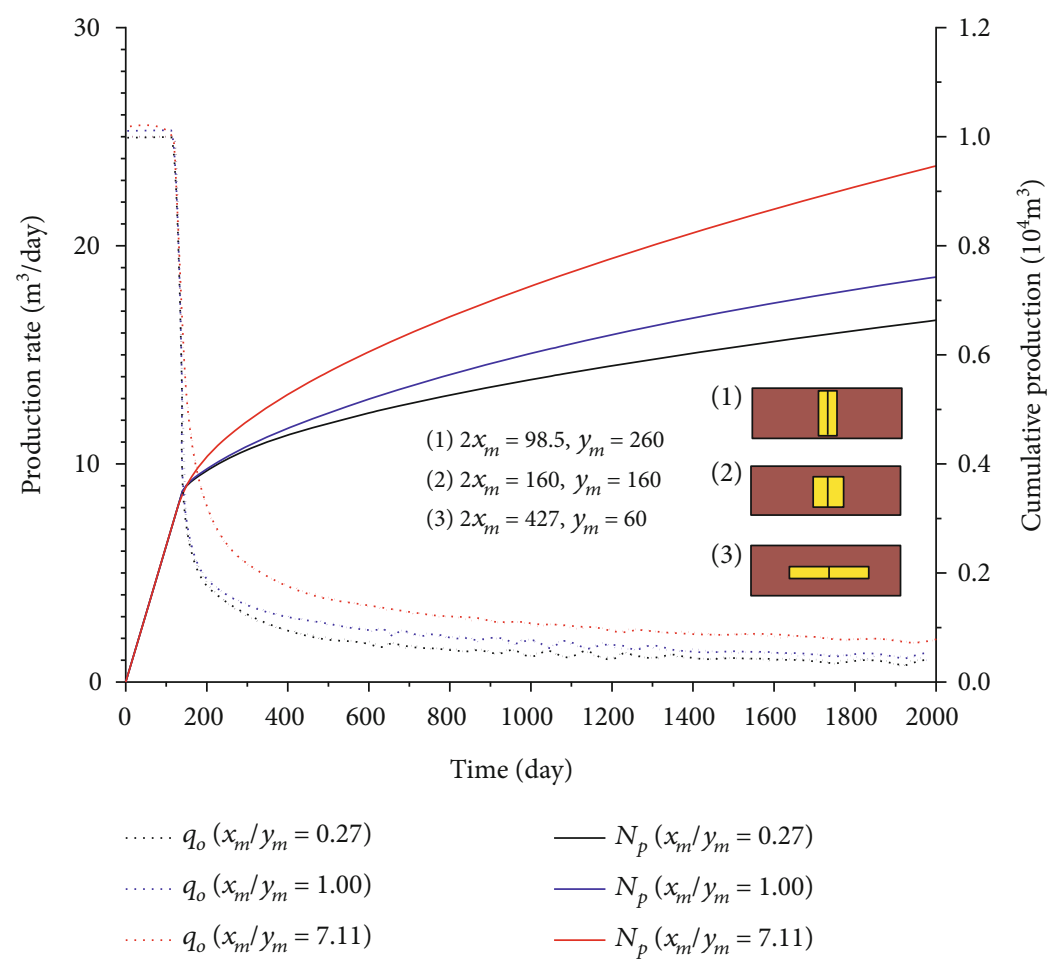

FIGURE 13: The effect of SRV shape on flow rate and cumulative yield (compound working system).

production is begun at a constant rate, and well bottom pressure declines rapidly. When wellbore pressure declines to a limiting value, the producing rate begins to decline as the well produces against a constant pressure [32]. The compound working system developed in this work enables the prediction of long-term wells' performance with a high level of accuracy. It is very consistent with the actual production situation of oil wells. 


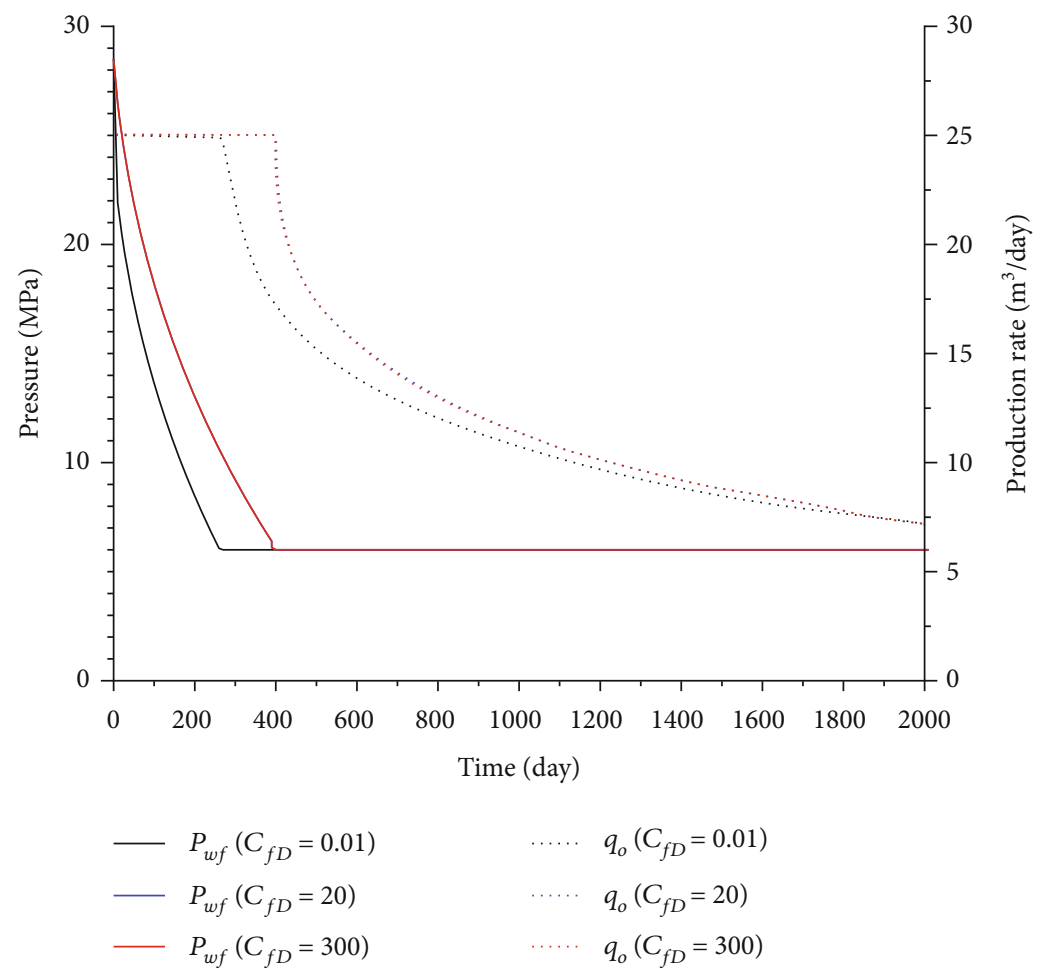

FIGURE 14: The effect of fracture conductivity on well performance (compound working system).

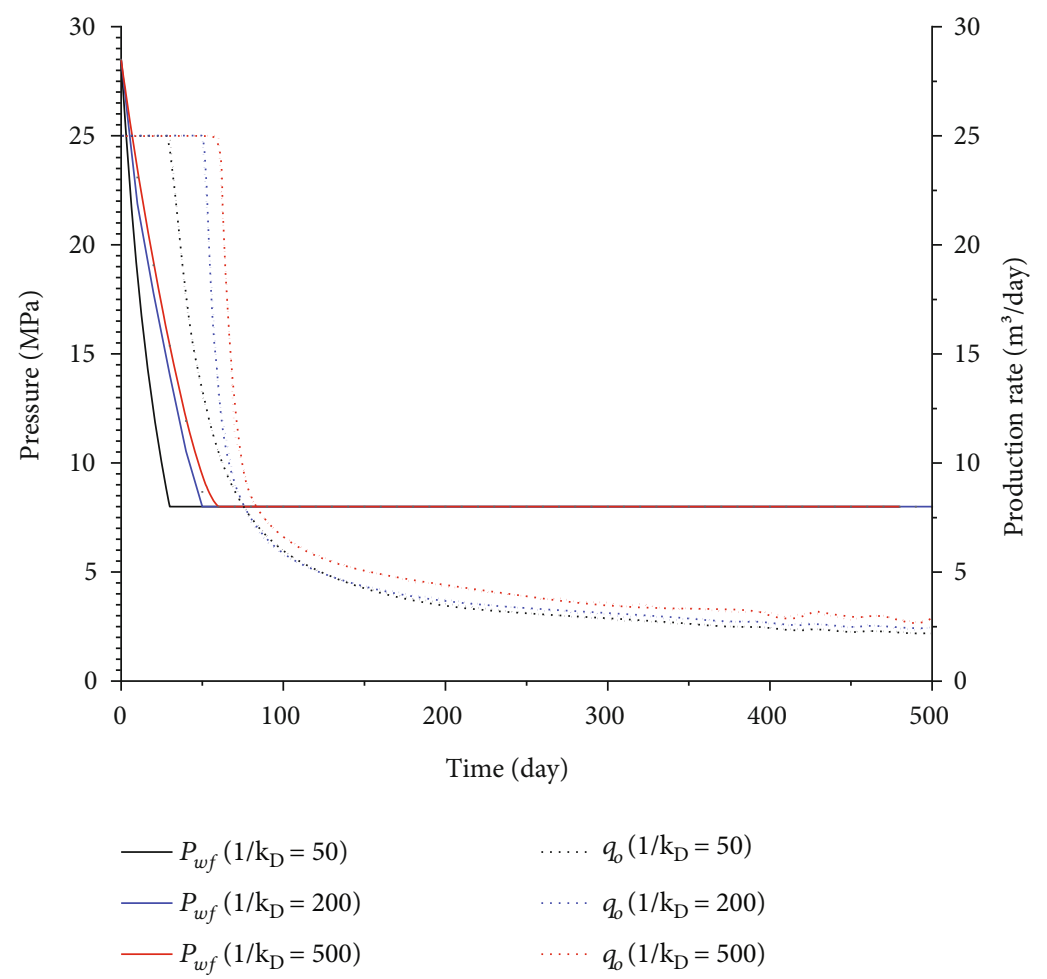

FIGURE 15: The effect of mobility ratio on well performance (compound working system).

3.3.1. Shape and Size of Stimulated Reservoir Volume. The effects of SRV size and shape on the production rate are shown in Figures 12 and 13, which demonstrate their significant influences on both the flow rate and cumulative pro- duction. Comparing the three models shown in Figure 12, the larger the SRV size is, the longer the constant flow period and the higher cumulative production. The larger size effect is to extend the constant period by about $166 \%$ and increase 


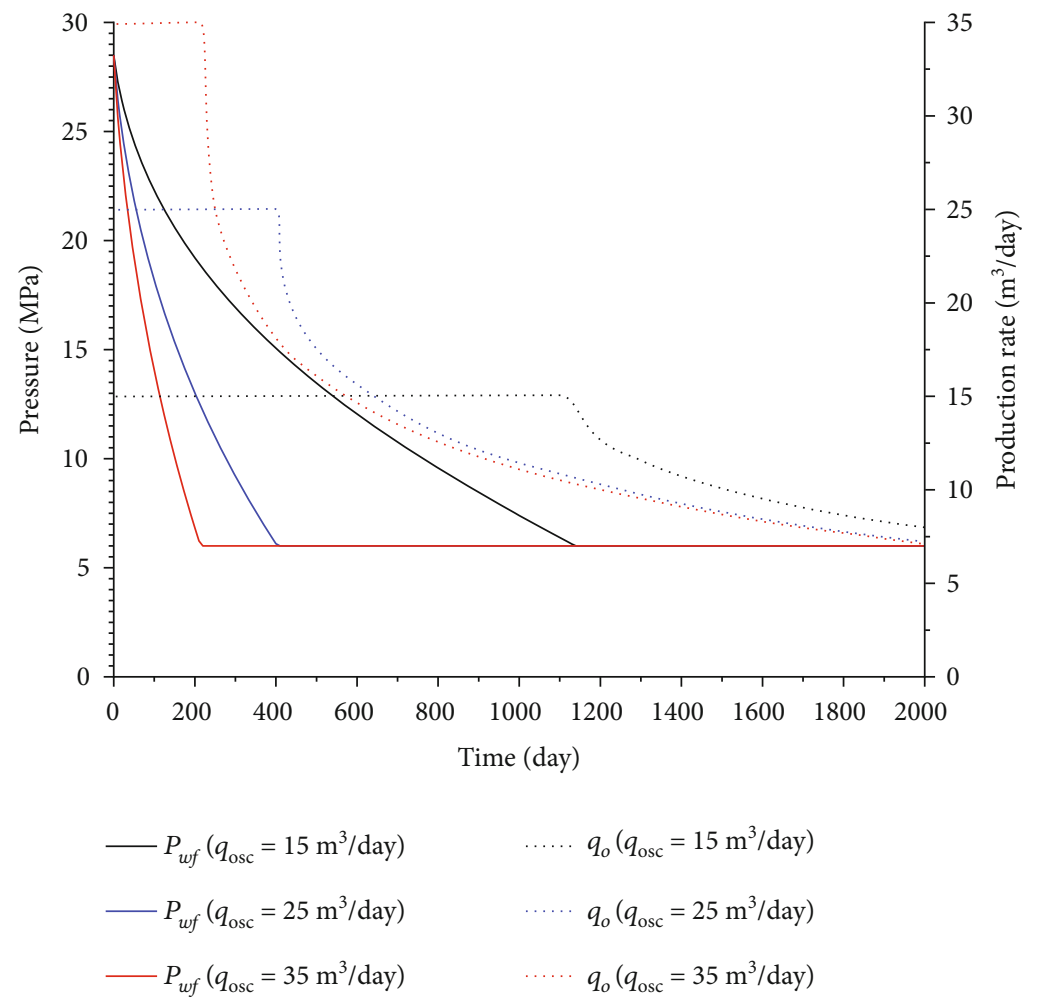

FIGURE 16: Effect of initial flow rate on the performance curve (compound working system).

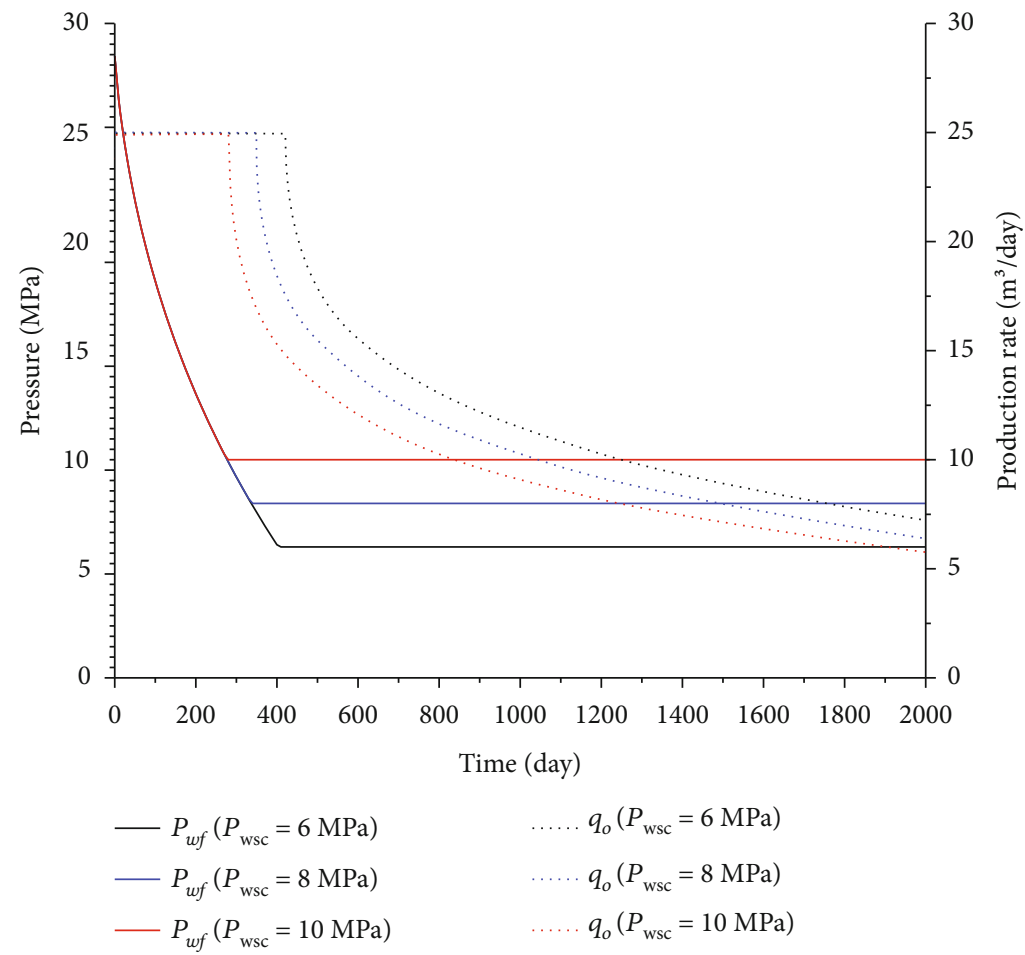

FIGURE 17: Effect of limiting wellbore pressure on well performance curve (compound working system).

the cumulative production by about $30 \%$. However, the rate difference becomes minimal after 500 days. This is because the SRV region's oil yield has been primarily produced, leaving other regions to be the dominant factors for production.
Figure 13 shows that when the SRV region's length-width ratio increases, the flow rate is higher. In other words, an SRV shape similar to the formation can help increase productivity. The effect of the $x$-direction rectangular shape of the SRV 
increases the cumulative production by about $56 \%$. In the initial period, flow only happens in the hydraulic fractures and the stimulated region near the well. Therefore, producing rate is not affected by the shape and size of the SRV. In the exploitation process, the production wave spreads to the SRV region's edges, and reservoirs with a similar shape to the SRV have a higher harvest. Therefore, in the fracturing design, the stimulated reservoir volume size and shape should be seriously discussed.

3.3.2. Fracture Conductivity and Mobility Ratio. The effect of fracture conductivity $\left(C_{f D}=0.01,20,300\right)$ under the compound working system is shown in Figure 14. For a fracture conductivity of 0.01 (and other properties and parameters remaining constant), the production period at a constant rate lasts only $270 \mathrm{~d}$. For fracture conductivities of 20 and 300, the period increases to $410 \mathrm{~d}$, i.e., an increase of $51.9 \%$. Moreover, the flow rate decreases rapidly in the constant pressure stage. These results demonstrate that the fracture conductivity helps extend the stable production period and achieve higher production within a short time.

The influence of the mobility ratio between the SRV region and matrix area on the dimensionless pressure is shown in Figure 15. Here, the SRV permeability of $k_{4}$ is varied while keeping the well and oil characteristics constant. It can be seen that with the value of mobility ratio increasing, the producing period at a constant rate extends by $150 \%$, and the rate of pressure decline decreases. This is because improving the permeability of the SRV aids fluid flow.

3.3.3. Initial Flow Rate and Limiting Wellbore Pressure. Plots of producing rate and wellbore pressure vs. time for different initial flow rates $\left(q_{o i}=15,25,35 \mathrm{~m}^{3} /\right.$ day $)$ are shown in Figure 16. The producing rate decreases from $35 \mathrm{~m}^{3} /$ day to $15 \mathrm{~m}^{3} /$ day while the stable production period increases from $220 \mathrm{~d}$ to $1140 \mathrm{~d}$. The effect of the lower initial flow rate is to extend the producing period at a constant rate of about $418 \%$. Pressure decline at the wellbore steadily decreases during this period. Within a short period of time, a higher cumulative yield can be obtained. However, the ultimate recovery is not significantly different.

Plots of producing rate and wellbore pressure vs. time for limiting wellbore pressure $\left(p_{w f s c}=6,8,10 \mathrm{MPa}\right)$ are shown in Figure 17. The conversion pressure decreases from $10 \mathrm{MPa}$ to $6 \mathrm{MPa}$, while the stable production stage increases by $46 \%$ from $280 \mathrm{~d}$ to $410 \mathrm{~d}$. The pressure drop rate is consistent, but the final output increases by $23 \%$ from $2.6856 \times 104 \mathrm{~m}^{3}$ to $3.2668 \times 104 \mathrm{~m}^{3}$. This shows that the conversion pressure can effectively extend the first period and significantly increase the well's ultimate production at the same initial flow rate.

\section{Conclusions}

This paper presents a semianalytical model to simulate the flow through a vertical well with branch fractures surrounded by a nonstimulated zone. The specific conclusions are as follows:
(1) A practical semianalytical model of ultralowpermeability reservoir with SRV is established based on the five-linear flow model and the fracture conductivity influence function

(2) The effects of critical parameters including SRV size and shape, fracture conductivity, mobility ratio, initial flow rate, and limiting wellbore pressure under different working systems are analysed

(3) The prediction results of constant production and constant pressure working systems show that a large SRV size can effectively stabilize oil production and reduce formation energy losses. Specifically, (i) an SRV similar in shape to the formation can stimulate the ultimate recovery rate, and (ii) for an SRV with constant shape and size, the larger the effective SRV, the better the well performance

(4) The prediction of long-term oil well performance under the compound working system shows that (i) SRV size, permeability, and initial flow rate can effectively prolong the constant rate period. Among them, the initial flow rate can extend by $418 \%$. (ii) The SRV size and shape and conversion pressure can significantly improve the ultimate recovery rate. The SRV shape similar to the reservoir shape increases it by $56 \%$

\section{Appendix}

\section{A. Dimensionless Variables}

Dimensionless pressure:

$$
p_{j D}=\frac{\alpha_{p} k_{4} h}{q \mu B}\left(p_{i}-p_{j}\right), \quad j=1,2,3,4
$$

Dimensionless time:

$$
t_{D}=\frac{\alpha_{t} k_{4}}{\phi \mu c_{t} y_{f}^{2}} t
$$

Dimensionless distances:

$$
\begin{aligned}
& x_{D}=\frac{x}{y_{f}}, \\
& y_{D}=\frac{y}{y_{f}} .
\end{aligned}
$$

Dimensionless fracture and reservoir conductivity, respectively:

$$
\begin{aligned}
& C_{f D}=\frac{k_{f} w_{f}}{k_{4} y_{f}}, \\
& C_{R D}=\frac{k_{4} y_{f}}{k_{2} y_{e}} .
\end{aligned}
$$


Dual-porosity parameters:

$$
\begin{gathered}
\omega=\frac{\left(\phi c_{t}\right)_{4 f}}{\left(\phi c_{t}\right)_{4 f}+\left(\phi c_{t}\right)_{4 m}}, \\
\lambda=\sigma y_{f}^{2} \frac{k_{4 m}}{k_{4 f}}, \\
\sigma=4\left(\frac{1}{L_{x}^{2}}+\frac{1}{L_{y}^{2}}+\frac{1}{L_{z}^{2}}\right) .
\end{gathered}
$$

This paper assumes square matrix blocks of size $L$ and uses $\sigma=12 / L^{2}$ to compute the shape factor.

Dimensionless diffusivity for five regions:

$$
\begin{gathered}
\eta_{j D}=\frac{\eta_{j}}{\eta_{4}} \\
\eta_{j}=\alpha_{t} \frac{k_{j}}{\left(\phi c_{t}\right)_{j} \mu}(j=1,2,3 \text {, or } 4 \text { indicates region }) .
\end{gathered}
$$

Mobility ratio:

$$
k_{D}=\frac{\mu_{4} k_{j}}{\mu_{j} k_{4}}(j=1,2, \text { or } 3 \text { indicates region })
$$

\section{B. Model Derivation and Solution}

The suggested solution is based on the assumption that flow within each region is $1 \mathrm{D}$ and can be represented by a combination of flows within contiguous regions. Laplace transformation concerning $t_{D}$ is applied to Equations (2)-(21) to solve the dimensionless pressure distribution under the condition of constant flow.

B.1. Equation and Boundary Conditions for Region 1. In Region 1 , the flow is one-dimensional and in the $y$-direction. Considering the symmetry, the dimensionless governing equations are as follows:

$$
\begin{gathered}
\frac{\partial^{2} \tilde{p}_{1 D}}{\partial y_{D}^{2}}=\frac{1}{\eta_{1 D}} s \tilde{p}_{1 D}, \\
x_{w D}+x_{m D} \leq x_{D} \leq x_{e D}, \\
y_{w D}+1 \leq y_{D} \leq y_{D} .
\end{gathered}
$$

Boundary condition 1: no-flow condition at the outer reservoir boundary $\left(y=y_{e}\right)$

$$
\frac{\partial \tilde{p}_{1 D}\left(x_{D}, y_{e D}, s\right)}{\partial y_{D}}=0
$$

Boundary condition 2: pressure and production continuity between Regions 1 and $3\left(y=y_{w}+y_{f}\right)$

$$
\tilde{p}_{1 D}\left(x_{D}, y_{w D}+1, s\right)=\tilde{p}_{3 D}\left(x_{D}, y_{w D}+1, s\right)
$$

The general form of the solution for Equation (B.1) can be written as

$$
\frac{\partial \tilde{p}_{1 D}\left(x_{D}, y_{w \mathrm{D}}+1, s\right)}{\partial y_{D}}=\frac{\partial \tilde{p}_{3 D}\left(x_{D}, y_{w D}+1, s\right)}{\partial y_{D}}
$$

By applying the external boundary condition given by Equation (B.2), we obtain $B=0$. By applying the inner boundary condition given by Equation (B.3), we obtain

$$
\tilde{p}_{1 D}=A \cosh \left[\left(y_{e D}-y_{D}\right) \sqrt{\frac{s}{\eta_{1 D}}}\right]+B \sin \mathrm{h}\left[\left(y_{e D}-y_{D}\right) \sqrt{\frac{s}{\eta_{1 D}}}\right] \text {. }
$$

Therefore, the pressure for Region 1 can be rewritten in terms of the pressure for Region 3 as

$$
A=\frac{\tilde{p}_{3 D}}{\cosh \left[\left(y_{e D}-y_{w D}-1\right) \sqrt{s / \eta_{1 D}}\right]} .
$$

Based on Equations (B.3), (B.4), (B.5), and (B.6), the flow rate between Regions 1 and 3 is equal to $\left(y_{D}=y_{w D}+1\right)$

$$
\begin{aligned}
\tilde{p}_{1 D} & =\tilde{p}_{3 D} \cdot \frac{\cosh \left[\left(y_{e D}-y_{D}\right) \sqrt{s / \eta_{1 D}}\right]}{\cosh \left[\left(y_{e D}-y_{w D}-1\right) \sqrt{s / \eta_{1 D}}\right]}, \\
\frac{\partial \tilde{p}_{1 D}}{\partial y_{D}} & =\tilde{p}_{3 D} \sqrt{\frac{s}{\eta_{1 D}}} \tan \mathrm{h}\left[\left(y_{e D}-y_{w D}-1\right) \sqrt{\frac{s}{\eta_{1 D}}}\right] .
\end{aligned}
$$

B.2. Equation and Boundary Conditions for Region 2. In Region 2, the flow is approximated by the $y$-direction flow. Considering the symmetry, the dimensionless governing equations are as follows:

$$
\begin{aligned}
\frac{\partial^{2} \tilde{p}_{2 D}}{\partial y_{D}^{2}} & =\frac{1}{\eta_{2 D}} s \tilde{p}_{2 D}, \\
x_{w D} & \leq x_{D} \leq x_{w m D}, \\
y_{w D}+1 & \leq y_{D} \leq y_{e D} .
\end{aligned}
$$

Boundary condition 1: no-flow condition at the outer reservoir boundary

$$
\frac{\partial \tilde{p}_{2 D}\left(x_{D}, y_{e D}, s\right)}{\partial y_{D}}=0
$$

Boundary condition 2: pressure and flux continuity between Regions 2 and $4\left(y=y_{w}+y_{f}\right)$

$$
\begin{gathered}
\tilde{p}_{2 D}\left(x_{D}, y_{w D}+1, s\right)=\tilde{p}_{4 D}\left(x_{D}, y_{\mathrm{wD}}+1, s\right) s \\
\frac{k}{\mu} \frac{\tilde{p}_{2 D}\left(x_{D}, y_{w D}+1, s\right)}{\partial y_{D}}=\frac{k_{4 f}}{\mu} \frac{\partial \tilde{p}_{4 D}\left(x_{D}, y_{\mathrm{wD}}+1, s\right)}{\partial y_{D}} .
\end{gathered}
$$


The general form of the solution for Equation (B.9) can be given as

$\tilde{p}_{2 D}=C \cosh \left[\left(y_{e D}-y_{D}\right) \sqrt{\frac{s}{\eta_{2 D}}}\right]+D \sinh \left[\left(y_{e D}-y_{D}\right) \sqrt{\frac{s}{\eta_{2 D}}}\right]$.

By applying the external boundary condition given by Equation (B.10), we obtain $D=0$. By applying the inner boundary condition given by Equation (B.11), we obtain

$$
C=\frac{\tilde{p}_{4 D}}{\cosh \left[\left(y_{e D}-y_{w D}-1\right) \sqrt{s / \eta_{2 D}}\right]}
$$

Therefore, the pressure in Region 2 can be rewritten in terms of the pressure in Region 4 at the boundary and given by

$$
\tilde{p}_{2 D}=\tilde{p}_{4 D} \cdot \frac{\cos \mathrm{h}\left[\left(y_{e D}-y_{D}\right) \sqrt{s / \eta_{2 D}}\right]}{\cosh \left[\left(y_{e D}-y_{w D}-1\right) \sqrt{s / \eta_{2 D}}\right]}
$$

The flux between Regions 2 and 4 is equal to $\left(y_{D}=y_{w D}+1\right)$

$$
\frac{\partial \tilde{p}_{2 D}}{\partial y_{D}}=\tilde{p}_{4 D} \sqrt{\frac{s}{\eta_{2 D}}} \tan \mathrm{h}\left[\left(y_{e D}-y_{w D}-1\right) \sqrt{\frac{s}{\eta_{2 D}}}\right] .
$$

B.3. Equation and Boundary Conditions for Region 3. In Region 3, the dimensionless governing equations are as follows:

$$
\frac{\partial^{2} \tilde{p}_{3 D}}{\partial x_{D}^{2}}+\frac{\partial p_{1 D}\left(y_{w D}+1, s\right)}{\partial y_{D}}=\frac{1}{\eta_{3 D}} s \tilde{p}_{3 D}
$$

Boundary condition 1: no-flow condition at the outer reservoir boundary

$$
\frac{\partial \tilde{p}_{3 D}\left(x_{e D}, y_{D}, s\right)}{\partial x_{D}}=0
$$

Boundary condition 2: pressure and flux continuity between Regions 2 and $4\left(x=x_{w}+x_{m}\right)$

$$
\begin{array}{r}
\tilde{p}_{3 D}\left(x_{w m D}, y_{D}, s\right)=\tilde{p}_{4 D}\left(x_{w m D}, y_{D}, s\right), \\
\frac{k}{\mu} \frac{\partial \tilde{p}_{3 D}\left(x_{w m D}, s\right)}{\partial x_{D}}=\frac{k_{4 f}}{\mu} \frac{\partial \tilde{p}_{4 D}\left(x_{w m D}, s\right)}{\partial x_{D}} .
\end{array}
$$

Using Equation (B.8) and assuming that $p_{3 D}$ does not depend on $y_{D}$, Equation (B.17) can be rewritten as

$$
\frac{d \tilde{p}_{3 D}}{d x_{D}^{2}}-C_{1}(s) \tilde{p}_{3 D}=0
$$

where

$$
C_{1}(s)=\frac{s}{\eta_{3 D}}+\sqrt{\frac{s}{\eta_{3 D}}} \cdot \tan \mathrm{h}\left[\left(y_{e D}-y_{w D}-1\right) \sqrt{\frac{s}{\eta_{3 D}}}\right] .
$$

The general form of the solution for Equation (B.21) can be given as

$\tilde{p}_{3 D}=E \cosh \left[\left(x_{e D}-x_{D}\right) \sqrt{C_{1}(s)}\right]+F \sin \mathrm{h}\left[\left(x_{e D}-x_{D}\right) \sqrt{C_{1}(s)}\right.$.

By applying the external boundary condition given by Equation (B.18), we obtain $F=0$. By applying the inner boundary condition given by Equation (B.19), we obtain

$$
E=\frac{\tilde{p}_{4 D}}{\cosh \left[\left(x_{e D}-x_{w m D}\right) \sqrt{C_{1}(s)}\right]} .
$$

Therefore, the pressure in Region 3 can be rewritten in terms of the pressure in Region 4 at the boundary and given by

$$
\tilde{p}_{3 D}=\tilde{p}_{4 D} \cdot \frac{\cosh \left[\left(x_{e D}-x_{D}\right) \sqrt{C_{1}(s)}\right]}{\cosh \left[\left(x_{e D}-x_{w m D}\right) \sqrt{C_{1}(s)}\right]} .
$$

The flow rate between Regions 3 and 4 is equal to $\left(x_{D}=\right.$ $\left.x_{w m D}\right)$

$$
\frac{\partial \tilde{p}_{3 D}}{\partial x_{D}}=\tilde{p}_{4 D} \sqrt{C_{1}(s)} \tan \mathrm{h}\left[\left(x_{e D}-x_{w m D}\right) \sqrt{C_{1}(s)}\right] .
$$

B.4. Equation and Boundary Conditions for Region 4. In Region 4, the dimensionless governing equations are as follows:

$$
\frac{\partial^{2} \tilde{p}_{4 D}}{\partial x_{D}^{2}}+\frac{1}{y_{e D} C_{R D}} \frac{\partial \tilde{p}_{2 D}\left(y_{w D}+1, s\right)}{\partial y_{D}}=u(s) \tilde{p}_{4 D}
$$

where

$$
\begin{gathered}
u(s)=s f(s), \\
\begin{cases}1, & \text { for homogeneous SRV region, } \\
\frac{s \omega(1-\omega)+\lambda}{s(1-\omega)+\lambda}, & \text { for dual - porosity SRV region. }\end{cases}
\end{gathered}
$$

Boundary condition: the production of the wellbore is constant

$$
\frac{\partial \tilde{p}_{4 D}\left(x_{w D}, s\right)}{\partial x_{D}}=-\frac{\pi}{2} \cdot \frac{1}{s}
$$


Using Equation (B.16) and assuming that $p_{4 D}$ does not depend on $y_{D}$, Equation (B.27) can be rewritten as

$$
\frac{d \tilde{p}_{4 D}}{d x_{D}^{2}}-C_{2}(s) \tilde{p}_{4 D}=0
$$

where

$$
C_{2}(s)=u(s)+k_{D} \sqrt{\frac{s}{\eta_{2 D}}} \cdot \tan \mathrm{h}\left[\left(y_{e D}-y_{w D}-1\right) \sqrt{\frac{s}{\eta_{2 D}}}\right] .
$$

The general form of the solution for Equation (B.30) can be given as

$\tilde{p}_{4 D}=G \cosh \left[\left(x_{w m D}-x_{D}\right) \sqrt{C_{2}(s)}\right]+H \sinh \left[\left(x_{w m D}-x_{D}\right) \sqrt{C_{2}(s)}\right]$.

By applying the outer boundary condition given by Equations (B.19) and (B.20), we obtain

$$
\begin{gathered}
E \cosh \left[\left(x_{e D}-x_{w m D}\right) \sqrt{C_{1}(s)}\right]=G \\
E k_{D} \sqrt{C_{1}(s)} \sinh \left[\left(x_{e D}-x_{w m D}\right) \sqrt{C_{1}(s)}\right]=\sqrt{C_{2}(s)} H .
\end{gathered}
$$

By applying the inner boundary condition given by Equation (B.29), we obtain

$\frac{\pi}{2} \cdot \frac{1}{s}=\sqrt{C_{2}(s)} G \sin \mathrm{h}\left[x_{m D} \sqrt{C_{2}(s)}\right]+\sqrt{C_{2}(s)} H \cos \mathrm{h}\left[x_{m D} \sqrt{C_{2}(s)}\right]$.

Therefore, the pressure in Region 4 is as follows:

$$
\begin{aligned}
& \tilde{p}_{4 D}= \frac{\pi}{2} \cdot \frac{1}{\sqrt{C_{2}(s)}} \\
& \cdot \frac{1+k_{D} \sqrt{\left(C_{1}(s) / C_{2}(s)\right)} \tan \mathrm{h}\left[x_{m D} \sqrt{C_{2}(s)}\right] \tan \mathrm{h}\left[\left(x_{e D}-x_{w m D}\right) \sqrt{C_{1}(s)}\right]}{\tan \mathrm{h}\left[x_{m D} \sqrt{C_{2}(s)}\right]+k_{D} \sqrt{\left(C_{1}(s) / C_{2}(s)\right)} \tan \mathrm{h}\left[\left(x_{e D}-x_{w m D}\right) \sqrt{C_{1}(s)}\right]}, \\
& C_{1}(s)=\frac{s}{\eta_{3 D}}+\sqrt{\frac{s}{\eta_{3 D}}} \cdot \tan \mathrm{h}\left[\left(y_{e D}-y_{w D}-1\right) \sqrt{\frac{s}{\eta_{3 D}}}\right] \\
& C_{2}(s)=u(s)+k_{D} \sqrt{\frac{s}{\eta_{2 D}}} \cdot \tan \mathrm{h}\left[\left(y_{e D}-y_{w D}-1\right) \sqrt{\frac{s}{\eta_{2 D}}}\right] .
\end{aligned}
$$

As discussed in the paper's main body (Possible Model Modifications), modifications to this calculation procedure can readily be made to account for the gas case and wellbore storage.

\section{Nomenclature}

$B: \quad$ Oil formation volume factor $\left(\mathrm{m}^{3} / \mathrm{m}^{3}\right)$

$C_{f D}$ : Dimensionless fracture conductivity

$C_{f D o p t}$ : Optimal fracture conductivity

$c_{t}$ : Total compressibility of reservoir $\left(\mathrm{MPa}^{-1}\right)$

$h$ : Reservoir thickness (m)

$I_{y}: \quad$ Penetration ratio, dimensionless

$k$ : $\quad$ Matrix permeability $(\mathrm{mD})$

$k_{f}$ : $\quad$ Hydraulic fracture permeability $(\mathrm{mD})$

$k_{D}: \quad$ Mobility ratio

$k_{4}: \quad$ SRV region permeability $(\mathrm{mD})$

$p_{\mathrm{i}}: \quad$ Initial pressure $(\mathrm{MPa})$

$p_{j}: \quad$ Region $j$ pressure $(\mathrm{MPa})$

$p_{w f s c}: \quad$ Region $j$ pressure $(\mathrm{MPa})$

$p_{w}: \quad$ Wellbore pressure, dimensionless

$q$ : $\quad$ Production rate $\left(\mathrm{m}^{3} /\right.$ day $)$

$q_{o i}: \quad$ Initial flow rate $\left(\mathrm{m}^{3} /\right.$ day $)$

$s: \quad$ Laplace-transformation parameter

$t$ : Time (days)

$w_{f}$ : Width of hydraulic fractures (m)

$x: \quad x$-coordinate $(\mathrm{m})$

$x_{m}: \quad$ SRV region length $(\mathrm{m})$

$y: \quad y$-coordinate $(\mathrm{m})$

$y_{m}: \quad$ SRV region width $(\mathrm{m})$

$x_{e}: \quad$ Lateral boundary of reservoir $(\mathrm{m})$

$y_{e}: \quad$ Vertical boundary of reservoir (m)

$y_{f}: \quad$ Length of hydraulic fracture $(\mathrm{m})$

$x_{4}$ : Half-width of SRV (m)

$y_{4}: \quad$ Length of SRV (m)

$\varphi: \quad$ Reservoir porosity, fraction

$\lambda$ : $\quad$ Flow capacity ratio

$\omega: \quad$ Storativity ratio

$\alpha_{p}: \quad$ Unit conversion coefficient, $3.6 \times 24 \times 2 \pi \times 10^{-3}$

$\alpha_{t}$ : Unit conversion coefficient, $3.6 \times 24 \times 10^{-3}$.

\section{Subscripts}

$D$ : Dimensionless

e: Boundary

$f$ : Hydraulic fracture property

$j$ : Serial number of interface segments

$w$ : Wellbore property.

\section{Superscripts}

$\sim$ : Laplace transform.

\section{Data Availability}

The data used to support the findings of this study are included within the article.

\section{Conflicts of Interest}

The authors declare that there is no conflict of interest regarding the publication of this paper. 


\section{Acknowledgments}

This research was funded by the National Major Science and Technology Projects of China (grant number 2017ZX05030002).

\section{References}

[1] A. A. Daneshy, "Off-balance growth: a new concept in hydraulic fracturing," Journal of Petroleum Technology, vol. 55, no. 4, pp. 78-85, 2003.

[2] A. C. Gringarten, H. J. Ramey, and J. Henry, "Unsteady-state pressure distributions created by a well with a single horizontal fracture partial penetration or restricted entry," Society of Petroleum Engineers Journal, vol. 14, no. 4, pp. 413-426, 1974.

[3] S. T. Lee and J. R. Brockenbrough, "A new approximate analytic solution for finite-conductivity vertical fractures," SPE Formation Evaluation, vol. 1, no. 1, pp. 75-88, 1986.

[4] L. H. Cinco, V. F. Samaniego, and A. N. Dominguez, "Transient pressure behavior for a well with a finite-conductivity vertical fracture," Journal of Petroleum Technology, vol. 18, no. 4, pp. 253-264, 1978.

[5] L. H. Cinco and V. F. Samaniego, "Transient pressure analysis for fractured wells," Journal of Petroleum Technology, vol. 33, no. 9, pp. 1749-1766, 1981.

[6] L. H. Cinco, "Transient pressure analysis for fractured wells," in Paper SPE 10043 was presented at the International Petroleum Exhibition and Technical Symposium of the Society of Petroleum Engineers, pp. 18-26, Beijing, China, March, 1982.

[7] L. H. Cinco and H. Z. Meng, "Pressure transient analysis of wells with finite conductivity vertical fractures in double porosity reservoirs," in Paper SPE 18172 was presented at the SPE Annual Technical Conference and Exhibition, Houston, Texas, USA, October 1988.

[8] O. P. Houze, R. N. Horne, and J. J. Ramey, "Pressure-transient response of an infinite-conductivity vertical fracture in a reservoir with double-porosity behavior," SPE Formation Evaluation, vol. 3, no. 3, pp. 510-518, 1988.

[9] M. Brown, E. Ozkan, and R. Raghavan, "Practical solutions for pressure transient responses of fractured horizontal wells in unconventional reservoirs," in SPE Annual Technical Conference and Exhibition, vol. 47, pp. 4-7, New Orleans, LA, USA, October 2009.

[10] J. E. Warren and P. J. Root, "The behavior of naturally fractured reservoirs," Society of Petroleum Engineers Journal, vol. 3, no. 3, pp. 245-255, 1963.

[11] H. Kazemi, "Pressure transient analysis of naturally fractured reservoirs with uniform fracture distribution," Society of Petroleum Engineers Journal, vol. 9, no. 4, pp. 451-462, 1969.

[12] C. M. Du, X. Zhang, L. Zhan et al., "Modelling hydraulic fracturing induced fracture networks in shale gas reservoirs as a dual porosity system," in SPE International Oil and Gas Conference and Exhibition in China, Beijing, China, June 2010.

[13] I. Brohi, D. M. Pooladi, and R. Aguilera, "Modeling fractured horizontal wells as dual-porosity composite reservoirsapplication to tight gas shale gas and tight oil cases," in SPE Western North American Region Meeting, pp. 7-11, Anchorage, AK, USA, May 2011.

[14] E. Stalgorova and L. Mattar, "Practical analytical model to simulate production of horizontal wells with branch fractures," in
SPE Canadian Unconventional Resources Conference, Calgary, AB, Canada, November 2012.

[15] E. Stalgorova and L. Mattar, "Analytical model for unconventional multi-fractured composite systems Ekaterina," in SPE Canadian Unconventional Resources Conference, Calgary, AB, Canada, November 2012.

[16] X. Liu and G. Zhao, "A fractal wormhole model for cold heavy oil production," Journal of Canadian Petroleum Technology, vol. 44, no. 9, pp. 31-36, 2005.

[17] X. Liu, C. Tian, and L. Jiang, "Steady state deliverability evaluation model of fracture network reconstruction vertical well in tight oil reservoir," Journal of Northeast Petroleum University, vol. 38, no. 1, pp. 91-97, 2014.

[18] J. Wang, X. Wang, and W. Dong, "A semianalytical model for multiple-fractured horizontal wells with SRV in tight oil reservoirs," Geofluids, vol. 2017, Article ID 2632896, 15 pages, 2017.

[19] B. Yuan, Z. Zhang, and C. R. Clarkson, "The generalized analytical model of transient linear flow in heterogeneous fractured liquid-rich tight reservoirs with non-static properties," Applied Mathematical Modelling, vol. 31, no. 6, pp. 78-81, 2006.

[20] M. Al-Kobaisi, E. Ozkan, and H. Kazemi, "A hybrid numerical-analytical model of finite-conductivity vertical fracture intercepted by a horizontal well," in SPE International Petroleum Conference in Mexico, pp. 8-9, Puebla, Mexico, November 2004.

[21] T. A. Blasingame and B. D. Poe, "Semianalytic solutions for a well with a single finite-conductivity vertical fracture," in 68th Annual Technical Conference and Exhibition of the Society of Petroleum Engineers, pp. 3-6, Houston, Texas, USA, October 1993.

[22] D. J. Wilkinsons, "New results for pressure transient behavior of hydraulically fractured wells," in SPE Joint Rocky Mountain Regional/Low Permeability Reservoirs Symposium and Exhibition, pp. 6-8, Denver, Colorado, USA, March 1989.

[23] X. Wang, W. Luo, X. Hou, and J. Wang, “Transient pressure analysis of multiple-fractured horizontal wells in boxed reservoirs," Petroleum Exploration and Development, vol. 44, no. 1, pp. 74-78, 2014.

[24] X. Wang, Y. Zhang, and C. Liu, "Productivity evaluation and conductivity optimization for vertically fractured wells," Petroleum Exploration and Development, vol. 31, no. 6, pp. 78-81, 2004.

[25] W. Lei, W. Xiao-dong, D. Xu-min, Z. Li, and L. Chen, "Rate decline curves analysis of a vertical fractured well with fracture face damage," Journal of Energy Resources Technology, vol. 134, no. 3, pp. 1-9, 2012.

[26] J. Wang, A. Jia, Y. Wei, and W. Zhao, "Pseudo steady productivity evaluation and optimization for horizontal well with multiple finite conductivity fractures in gas reservoirs," Journal of China University Petroleum, vol. 40, no. 1, pp. 100-107, 2016.

[27] W. Luo, X. Wang, P. Liu, and Q. Tian, "A simple and accurate calculation method for finite-conductivity fracture," Journal of Petroleum Science and Engineering, vol. 161, pp. 590-598, 2018.

[28] T. Feng, W. Xiaodong, Z. Yixuan, D. Xiaokang, and X. Wenli, "Production performance prediction of gas wells with compound working system," Special Oil and Gas Reservoirs, vol. 24, no. 2, pp. 99-102, 2017. 
[29] Y. Hu, S. Jia, J. Zhao et al., "Study on controlling conditions in network hydraulic fracturing," Journal of Southwest Petroleum University, vol. 35, no. 4, pp. 128-132, 2013.

[30] H. Stehfest, "Algorithm 368: numerical inversion of Laplace transforms [D5]," Communications of the ACM, vol. 13, no. 1, pp. 47-49, 1970.

[31] D. M. Anderson and L. Mattar, "An improved pseudo-time for gas reservoirs with significant transient flow," Journal of Canadian Petroleum Technology, vol. 46, no. 7, 2007.

[32] D. G. Russell, J. H. Goodrich, G. E. Perry, and J. F. Bruskotter, "Methods for predicting gas well performance," Journal of Petroleum Technology, vol. 18, no. 1, pp. 99-108, 1966. 